\title{
Determinants and Functions of CAFs Secretome During Cancer Progression and Therapy
}

\author{
Jenniffer Linares ${ }^{1 \dagger}$, Juan A. Marín-Jiménez ${ }^{2 \dagger}$, Jordi Badia-Ramentol ${ }^{1}$ and \\ Alexandre Calon ${ }^{1 *}$ \\ ${ }^{1}$ Cancer Research Program, Hospital del Mar Medical Research Institute (IMIM), Barcelona, Spain, ${ }^{2}$ Department of Medical \\ Oncology, Catalan Institute of Oncology (ICO) - L'Hospitalet de Llobregat, Barcelona, Spain
}

OPEN ACCESS

Edited by:

Marzia Di Donato,

University of Campania Luigi

Vanvitelli, Italy

Reviewed by:

Ferdinando Auricchio,

Second University of Naples, Italy

Paolo Paoli,

University of Florence, Italy

Fernando Calvo,

Consejo Superior de Investigaciones

Cientificas (CSIC), Spain

*Correspondence:

Alexandre Calon

acalon@imim.es

tThese authors have contributed equally to this work and share first authorship

Specialty section:

This article was submitted to Molecular and Cellular Oncology,

a section of the journal

Frontiers in Cell and Developmental

Biology

Received: 24 October 2020 Accepted: 07 December 2020

Published: 22 January 2021

Citation

Linares J, Marín-Jiménez JA Badia-Ramentol J and Calon A (2021)

Determinants and Functions of

CAFs Secretome During Cancer

Progression and Therapy.

Front. Cell Dev. Biol. 8:621070.

doi: 10.3389/fcell.2020.621070
Multiple lines of evidence are indicating that cancer development and malignant progression are not exclusively epithelial cancer cell-autonomous processes but may also depend on crosstalk with the surrounding tumor microenvironment (TME). Cancer-associated fibroblasts (CAFs) are abundantly represented in the TME and are continuously interacting with cancer cells. CAFs are regulating key mechanisms during progression to metastasis and response to treatment by enhancing cancer cells survival and aggressiveness. The latest advances in CAFs biology are pointing to CAFs-secreted factors as druggable targets and companion tools for cancer diagnosis and prognosis. Especially, extensive research conducted in the recent years has underscored the potential of several cytokines as actionable biomarkers that are currently evaluated in the clinical setting. In this review, we explore the current understanding of CAFs secretome determinants and functions to discuss their clinical implication in oncology.

\footnotetext{
Keywords: cancer-associated fibroblast (CAF), secretome, secreted factors, growth factors, cancer, tumor microenvironment (TME), metastasis, therapy
}

\section{INTRODUCTION}

Cancer-associated fibroblasts (CAFs) are contributing to the production of a wide variety of secreted factors impacting tumor progression by directly regulating malignant cancer cells aggressiveness or by indirectly reprogramming tumor immunity and angiogenesis (Sahai et al., 2020). Hence, molecular and functional inter- and intra-tumoral heterogeneity of CAFs has been a recent focus in oncology research. It is widely accepted that the functional phenotype of CAFs is in part determined by the cell of origin, including but not restricted to local resident fibroblasts (D'Arcangelo et al., 2020; Sahai et al., 2020). An alternative hypothesis advocating for CAF being a cell state depending on autocrine and paracrine signaling rather than a cell type has also been proposed (Kalluri, 2016). Whether CAFs functional heterogeneity is maintained among different solid tumor types or is a constant evolutionary state is still a debated question. However, recent studies have been investigating the determinants of CAFs secretome and their therapeutic interest across different tumor types. Molecular biomarkers predicting the risk of relapse and the potential benefit from treatments are currently needed for clinical decision-making. In an attempt to reach a more comprehensive evaluation of tumors, many CAFs-secreted factors have been included in gene expression signatures that are considered suitable prognostic tools for clinical diagnosis and prognostication (Berdiel-Acer et al., 2014; Karlan et al., 2014; Yue et al., 2019). As a matter of fact, recent advances in the understanding of CAFs secretome determinants and functions have brought to light the multiple benefits of using CAFs-secreted factors as actionable biomarkers for cancer diagnosis, treatment, and prognosis. 


\section{DETERMINANTS OF CAFS SECRETOME}

\section{Crosstalk With Tumor Cells and TME Components \\ Autocrine- and Paracrine-Secreted Factors}

Multiple autocrine loops impacting CAFs secretome have been discovered in the recent years (Figure 1). Among them, members of the transforming growth factor beta (TGF-beta) superfamily are known to be the main inducers of CAFs activation. Of note, CAFs secrete large amounts of TGF-beta isoforms 1, 2, and 3 (reviewed in Kalluri, 2016). In turn, secreted TGFbeta maintains a self-sustained active state -typically regarded as myofibroblasts- characterized by alpha smooth muscle actin (alpha-SMA) expression (Orimo et al., 2005; Kojima et al., 2010). Other members of the TGF-beta superfamily, such as Nodal, induce pro-tumorigenic phenotypes in fibroblasts from melanoma and colorectal cancer (CRC) (Li et al., 2019). Likewise, activin A has showed the ability to induce a secretory phenotype in CAFs via the SMAD-2-mediated transcriptional regulation of genes encoding extracellular matrix (ECM) components, ECM regulators, and soluble factors (Cangkrama et al., 2020). Alternatively, CAFs secretome may be maintained during tumor progression through enhanced stromal cell-derived factor (SDF)1 autocrine signaling loops and increased co-expression of receptors, such as TGF-beta-RI and CXC receptor (CXCR)4 (Kojima et al., 2010). In this sense, Scherz-Shouval et al. reported an increased production of TGF-beta-2 and SDF-1 factors by CAFs upon heat shock factor (HSF)-1 cytoplasmic translocation to the nucleus (Scherz-Shouval et al., 2014). HSF1 is a transcription factor that mediates the cellular response to

\footnotetext{
Abbreviations: AKT, protein kinase B; ATRA, all-trans retinoic acid; CCL, C$\mathrm{C}$ motif chemokine; COX2, cyclooxygenase 2; CXC, C-X-C motif chemokine; CXCL, CXC ligand; CXCR, CXC receptor; DKK-1, Dickkopf-related protein 1; FGF, fibroblast growth factor; GDF-15, growth differentiation factor 15; GM-CSF, granulocyte-macrophage colony-stimulating factor; HER3, epidermal growth factor receptor 3; HGF, hepatocyte growth factor; HIF, hypoxia-inducible factor; HspA1A, heat shock $70 \mathrm{kDa}$ protein 1A; ICAM-1, intercellular adhesion molecule 1; IFN, interferon; IGF, insulin-like growth factor; IGF1R, IGF 1 receptor; IGFBP, insulin-like growth factor-binding protein; JAK, Janus kinase; JNK, Jun N-terminal kinase; KLK, kallikrein; LIF, leukemia inhibitory factor; MCSF, macrophage colony-stimulating factor; MAPK, mitogen-activated protein kinase; MCP-1, monocyte chemoattractant protein 1; MIF, macrophage migration inhibitory factor; MMP, matrix metallopeptidase; mTOR, mammalian target of rapamycin; MYH-11, myosin 11; NF- $\mathrm{B}$, nuclear factor-kappa B; NRG, neuregulin; OXPHOS, oxidative phosphorylation system; P38 MAPK, p38 mitogen-activated protein kinase; PDGF, platelet-derived growth factor; PDGFRB, platelet-derived growth factor receptor beta; PDPN, podoplanin; PGE2, prostaglandin E2; PI3K, phosphoinositide 3-kinase; POSTN, periostin; PAR, protease-activated receptor; RAGE, receptor for advanced glycation end products; miRNA, microRNA; mRNA, messenger RNA; lncRNA, long non-coding RNA; S100A11, S100 calcium-binding protein A11; SATB-1, special AT-rich sequence-binding protein-1; SDF, stromal cell-derived factor; SFRP4, secreted frizzled-related protein 4;Shp, Src homology 2 containing protein tyrosine phosphatase; SMAD, acronym for a signal transducer family; SOCS, suppressor of cytokine signaling 1; STAT, signal transducer and activator of transcription; TAZ, transcriptional coactivator with PDZ-binding motif, also known as Wwtrl; TET, ten-eleven translocation enzyme; THBS, thrombospondin; TIMP, tissue inhibitors of MMP;TNC, tenascin C; TNF, tumor necrosis factor; TPL2, tumor progression locus 2; VCAM, vascular cell adhesion protein; VEGF, vascular endothelial growth factor; VEGFA, VEGF type A; YAP, yes-associated protein.
}

different types of stress, such as hypoxia or proteotoxic stress (Dayalan Naidu and Dinkova-Kostova, 2017).

Complex paracrine signaling through cancer cell-secreted factors also regulates CAFs secretome during tumor progression (Figure 1) and may depend on genetic alterations occurring in cancer cells. Indeed, KRAS mutant but not KRAS wildtype pancreatic ductal adenocarcinoma (PDAC) cancer cells induce CAFs activation through CXCR-2, leading to a nuclear factor-kappa B (NF- $\kappa \mathrm{B})$-mediated secretion of pro-tumoral cytokines interleukin (IL)-4, IL-10, and IL-13 (Awaji et al., 2020). Several additional studies have reported a pro-tumorigenic crosstalk between cancer cells and CAFs. For instance, kallikrein (KLK)-4 produced by malignant and premalignant prostate lesions can act on normal fibroblasts through the activation of protease-activated receptor (PAR)-1, which leads to a CAF proangiogenic secretory phenotype characterized by the increased expression of Dickkopf-related protein 1 (DKK-1), growth differentiation factor 15 (GDF-15), hepatocyte growth factor (HGF), IL-8, and vascular endothelial growth factor (VEGF) and the decreased expression of insulin-like growth factorbinding protein (IGFBP)-3, monocyte chemoattractant protein 1 (MCP-1), and platelet-derived growth factor (PDGF)-AA (Kryza et al., 2017). In PDAC, S100 calcium-binding protein A11 (S100A11) secreted by cancer cells activates the surrounding fibroblasts through the S100A11-receptor for advanced glycation end products (RAGE)-tumor progression locus 2 (TPL2)cyclooxygenase 2 (COX2) pathway to promote metastatic progression (Mitsui et al., 2019).

CAFs activation may also occur through paracrine signaling with non-cancer cells. For example, cytokines produced by immune cells during the inflammatory process may instruct CAFs function. Among them, IL-1 $\beta$ produced by immune cells in early hyperplastic lesions activates normal fibroblasts to become CAFs via the NF-кB pathway (Erez et al., 2010). Alternatively, granulin secretion by macrophages activates resident fibroblasts into tumor-promoting myofibroblasts sustaining metastatic growth in PDAC (Nielsen et al., 2016).

In addition to local intra-tumoral autocrine and paracrine signaling, systemic signaling involving steroid hormones, such as estrogens and androgens, is also able to modulate CAFs secretome, through binding to their receptors expressed in CAFs (Clocchiatti et al., 2018; Rothenberger et al., 2018). For instance, estrogens (E2) regulate the expression of several microRNAs (miRNAs) in breast cancer (BC)-derived CAFs (Vivacqua et al., 2019). In gastric cancer, estrogens stimulate CAFs secretion of IL-6, thereby promoting signal transducer and activator of transcription (STAT)-3 pathway-dependent cancer cells proliferation and invasion (Zhang Y. et al., 2020). Similarly, in prostate cancer $(\mathrm{PCa})$, the activation of CAFs-androgen receptor $(\mathrm{AR})$ with dihydrotestosterone modulates the secretion of pro-tumorigenic factors impacting cancer cell growth (Tanner et al., 2011). Conversely, AR blockade in CAFs decreases the expression of pro-tumorigenic factors, such as insulin-like growth factor (IGF)-1, fibroblast growth factor (FGF)-7, FGF-10, SDF-1, HGF, and TGF-beta 2 (Yu et al., 2013).

As illustrated by the opposite gene expression programs regulated upon FGF and TGF-beta pathway activation 


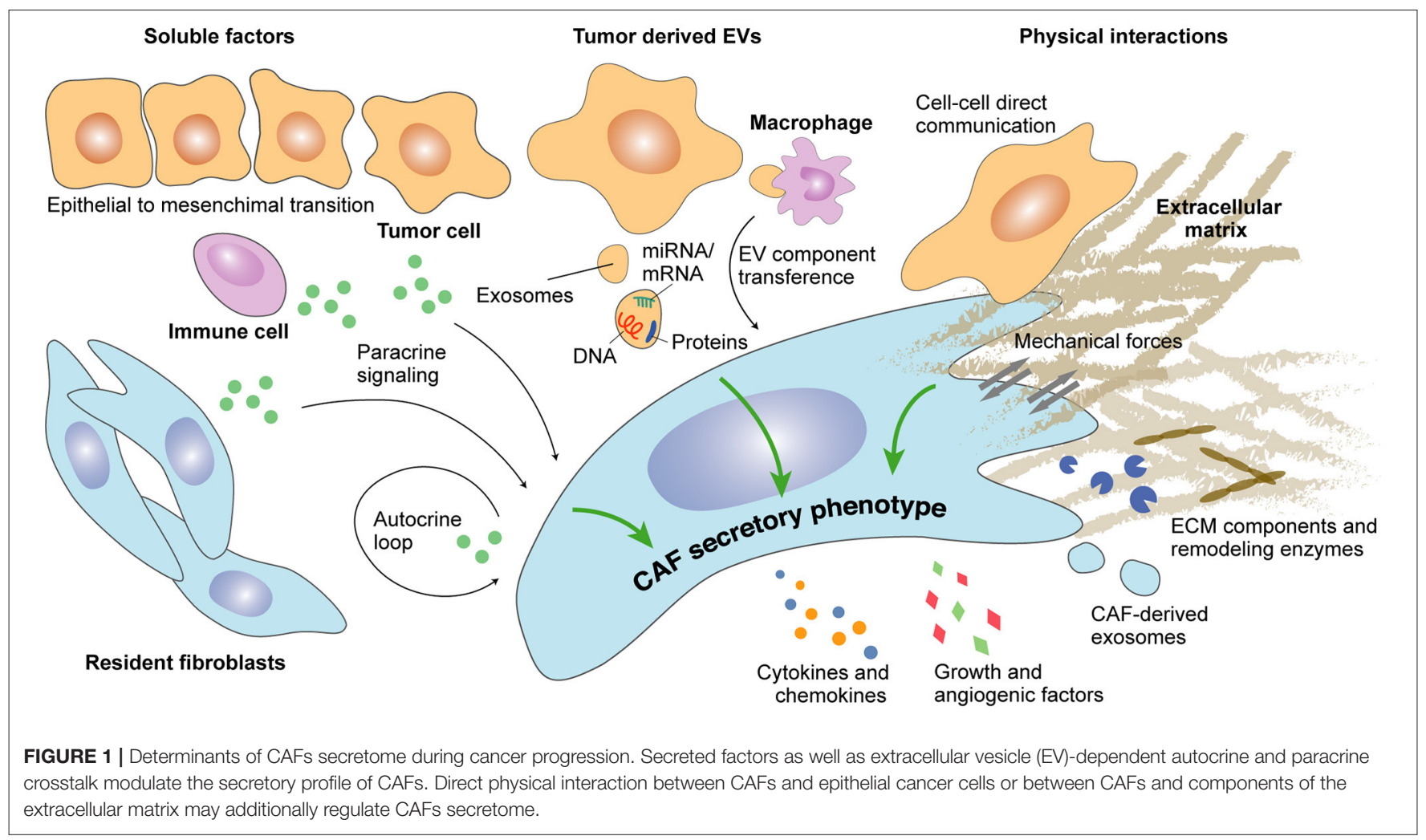

(Bordignon et al., 2019), CAFs secretome heterogeneity may be the result of a delicate balance between autocrine and paracrine signaling stimulated simultaneously and activating CAFs in different ways. It is worth noting that autocrine and paracrine triggering cues educating CAFs secretory functions may be tumor-dependent or even cancer subtype-dependent. Thus, the identification of multiple CAFs activation and secretion programs could greatly improve current molecular classification of cancer.

\section{Extracellular Vesicles}

Extracellular vesicles (EVs) are spherical membrane formations comprising exosomes and microvesicles, which can carry different molecules, such as proteins, DNAs, non-coding RNAs, and miRNAs/mRNAs. While both are playing a key role in distant intercellular communication, exosomes are derived from the endosomal system, and microvesicles are produced by the plasma membrane (reviewed in van Niel et al., 2018). EVbased intercellular communication between cancer cells and the tumor microenvironment (TME)-including CAFs (Figure 1)promotes cancer progression in multiple ways (reviewed in Han et al., 2019); however, EVs' ability to induce a secretory phenotype in CAFs still remains an open field of research (Webber et al., 2015). In some cases, tumor cell-derived EVs contain typical mitogenic factors, such as TGF-beta, which in ovarian cancer induces a pro-tumoral secretome leading to increased proliferation, motility, and invasiveness of ovarian cancer cells (Giusti et al., 2018). Furthermore, an increasing body of evidence points to the importance of EV-derived miRNA. For instance, in gastric cancer, EVs containing miR155, miR193b, and miR210 prime CAFs to secrete inflammatory chemokines, such as CXC ligand (CXCL)-1 and CXCL-8, through the activation of the Janus kinase (JAK)/STAT and NF-кB signaling pathways (Naito et al., 2019). Similarly, NF-кB activation in CAFs by EV-derived miR1247-3p in metastatic hepatocellular carcinoma (HCC) leads to a tumor-promoting secretion of IL-6 and IL-8 (Fang et al., 2018). Alternatively, EV-derived miR-210 and miR-155-5p induce a pro-angiogenic switch in CAFs through the activation of the JAK-2/STAT-3 pathway in lung cancer and melanoma (Zhou et al., 2018; Fan et al., 2020). Additional signaling pathways have been associated with miRNA-driven secretory stimulation. For instance, EVs containing miR-10b contribute to the enhanced TGF-beta expression in CAFs through the phosphoinositide 3-kinase (PI3K)/protein kinase B (AKT)/mammalian target of rapamycin (mTOR) signaling pathway in CRC (Dai et al., 2018). Finally, EVs containing coding mRNA have also been reported to trigger a secretory phenotype in CAFs. In this sense, cancer cellderived EVs containing mRNA coding for CXCR-4 and IGF-1R promote CAFs secretion of growth factors, such as VEGF in acute myeloid leukemia (Huan et al., 2013).

Interestingly, EV-induced CAFs may in turn shed additional EVs that will further support tumor growth by conferring enhanced proliferative and survival capabilities to cancer cells, thus establishing an EV-mediated bidirectional intercommunication (Savardashtaki et al., 2019; Yang et al., 2019). For instance, CAFs exposed to cancer cell-derived EVs in Hodgkin lymphoma are primed to secrete EVs together with pro-inflammatory cytokines and angiogenic factors (Dörsam 
et al., 2018). Similar to cancer cell-derived EVs, CAF-derived EVs contain commonly miRNA, which has been described to promote migration and resistance to treatment in several tumors (Dourado et al., 2019; Hu et al., 2019; Qin et al., 2019; Sun et al., 2019; Wang J.-W. et al., 2019). Besides miRNA, CAF-derived EVs containing mitochondrial mRNA can educate cancer cells to increase oxidative phosphorylation system (OXPHOS) metabolism, which consequently induces escape from dormancy (Sansone et al., 2017).

EV-mediated activation of CAFs can also occur indirectly through stromal cell mediators present in the TME. Indeed, a recent study showed that tumor-associated macrophages incorporate and transfer cancer cell-derived EVs to CAFs, which allows the formation of a pro-tumorigenic microenvironment (Umakoshi et al., 2019).

Moreover, EVs content may be changing during tumor progression, which could result in a temporal modulation of CAFs secretory phenotypes. Supporting this notion, EVs derived from primary or metastatic CRC promote different CAF functional profiles, switching from a pro-angiogenic to a more ECM remodeling phenotype (Rai et al., 2019). Therefore, EVmediated communication between tumor cells and CAFs may depend on alterations in the composition of secreted EVs during tumor progression. However, additional research is needed to confirm this hypothesis.

\section{Cell-Cell Contact and Mechanical Interactions}

CAFs/cancer cells physical interactions can modulate CAFs functions (Yamaguchi and Sakai, 2015), and the high complexity of this interplay has been recently illustrated (Arwert et al., 2020). For instance, CAFs may sense cancer cell genomic stress through cytoplasmic transcytosis and respond by expressing interferon (IFN)- $\beta 1$, leading to an increased production of chemokines, cytokines, and other inflammatory factors [CXCL-1 and 10, granulocyte-macrophage colony-stimulating factor (GM-CSF), macrophage migration inhibitory factor (MIF), IL-6, and IL-8, among others] (Arwert et al., 2020). Heterocellular gap junction communications have also been described between CAFs and cancer cells. This mechanism promoting epithelial-to-mesenchymal transition (EMT), migration, and invasiveness appears to be rather unidirectional-from CAFs toward cancer cell (Luo et al., 2018); however, a better understanding of the underlying molecular mechanisms is still required.

Mechano-sensing between CAFs and the surrounding ECM may equally modulate CAFs secretome. For example, matrix stiffness and contractile forces have been shown to determine CAFs behavior through different mechano-sensitive pathways. Among them, non-canonical YAP pathway activation is promoting CAFs ECM remodeling and angiogenic functions (Calvo et al., 2013). Indeed, secretion of pro-angiogenic VEGF-A by CAFs depends on factors involved in YAP pathway activation (Calvo et al., 2015).

These findings suggest a significant role of physical interactions in determining CAFs secretory phenotype. Remarkably, spatial (invasive front or tumor core) as well as temporal (early or late stage cancer) characteristics may influence mechano-sensing and should be considered when studying forces instructing CAFs secretory functions (Acerbi et al., 2015; Bauer et al., 2020).

\section{Spatial and Temporal Plasticity}

Intra-tumor heterogeneity of CAFs functional subtypes and their differential spatial pattern are already a widespread knowledge (Lambrechts et al., 2018; Awaji and Singh, 2019; Neuzillet et al., 2019). Thus, an effect of CAFs intra-tumoral location upon their secretory function may be expected. Remarkably, fibroblasts located next to the invasive front of BC show higher capacity to induce cancer cells migration and EMT in comparison with those located in the epicenter of the tumor (Gao et al., 2010). In pancreatic cancer, two spatially separated subtypes were identified (Figure 2). An inflammatory CAFs subtype (iCAFs), distant from cancer cells, showed a secretory phenotype with high interleukin and chemokine production [leukemia inhibitory factor (LIF), IL-6, IL-11, IL-1, CXCL-1] in comparison with periglandular myofibroblastic CAFs (myoCAFs), specialized in stromal remodeling functions (Öhlund et al., 2017). However, these two subtypes may be the borders of a functional spectrum depending on IL-1-R1 expression, conditioned by the balance between TGF-beta (pro-myoCAFs) and IL-1/JAK/STAT (proiCAFs) signaling activation (Biffi et al., 2019). An additional antigen-presenting CAFs (apCAFs) population activating CD4+ $\mathrm{T}$ cells was recently identified in PDAC (Figure 2), suggesting CAFs subtype-specific immunomodulatory capacity (Elyada et al., 2019). Along this line, Neuzillet and colleagues highlighted the complexity of CAFs heterogeneity in PDAC, describing at least four different functional and spatially distributed subtypes depending on periostin (POSTN), myosin 11 (MYH-11), and podoplanin (PDPN) expression (Neuzillet et al., 2019). Similarly, in BC (Figure 2), a subset of myofibroblastic CAFs (CAFS1: CD-29 ${ }^{\text {Med }}$ FAP $^{\text {Hi }}$ FSP-1 ${ }^{\text {Low-Hi }} \alpha$ SMA $^{\text {Hi }}$ PDGFRb $^{\text {Med-Hi }}$ CAV-1 ${ }^{\text {Low }}$ ) secreting differentially higher amount of CCL-11, CXCL-12, CXCL-13, and CXCL-14 was predominantly detected close to epithelial tumor cells (Costa et al., 2018). The other myofibroblastic $\left(\alpha \mathrm{SMA}^{\mathrm{Hi}}\right)$ CAF-S4 subtype was preferentially located within the tumor tissue, whereas CAF-S3 (FSP-1 ${ }^{\text {Med }}$ and $\mathrm{PDGFRb}^{\mathrm{Med}-\mathrm{Hi}}$ ) was detected in the juxta tumoral healthy tissue. CAF-S2 subtype (low or negative expression of stromal markers) appeared to be equally distributed in both areas (Costa et al., 2018).

For greater complexity, temporal evolution of CAFs during tumor progression makes it difficult to assess the exclusive effect of spatial distribution (Kalluri, 2016; D'Arcangelo et al., 2020). Indeed, Nidogen-2, a protein secreted by "vascular CAFs" in murine BC model, was firstly detected among perivascular cells but relocated within the tumor stroma at later stages of tumor progression (Bartoschek et al., 2018). In PDAC patients, different phenotypes were detected by CAFs secretome analysis of primary tumors and matched metastatic tissue (Öhlund et al., 2017). In addition, the above-mentioned S1 and S4 CAFs subsets have been recently found to be enriched in metastatic $\mathrm{BC}$ lymph nodes in comparison with matched primary tumor tissue (Costa et al., 2018; Pelon et al., 2020). In this setting, CXCL-12 secretion was found to be responsible of CAF-S1 

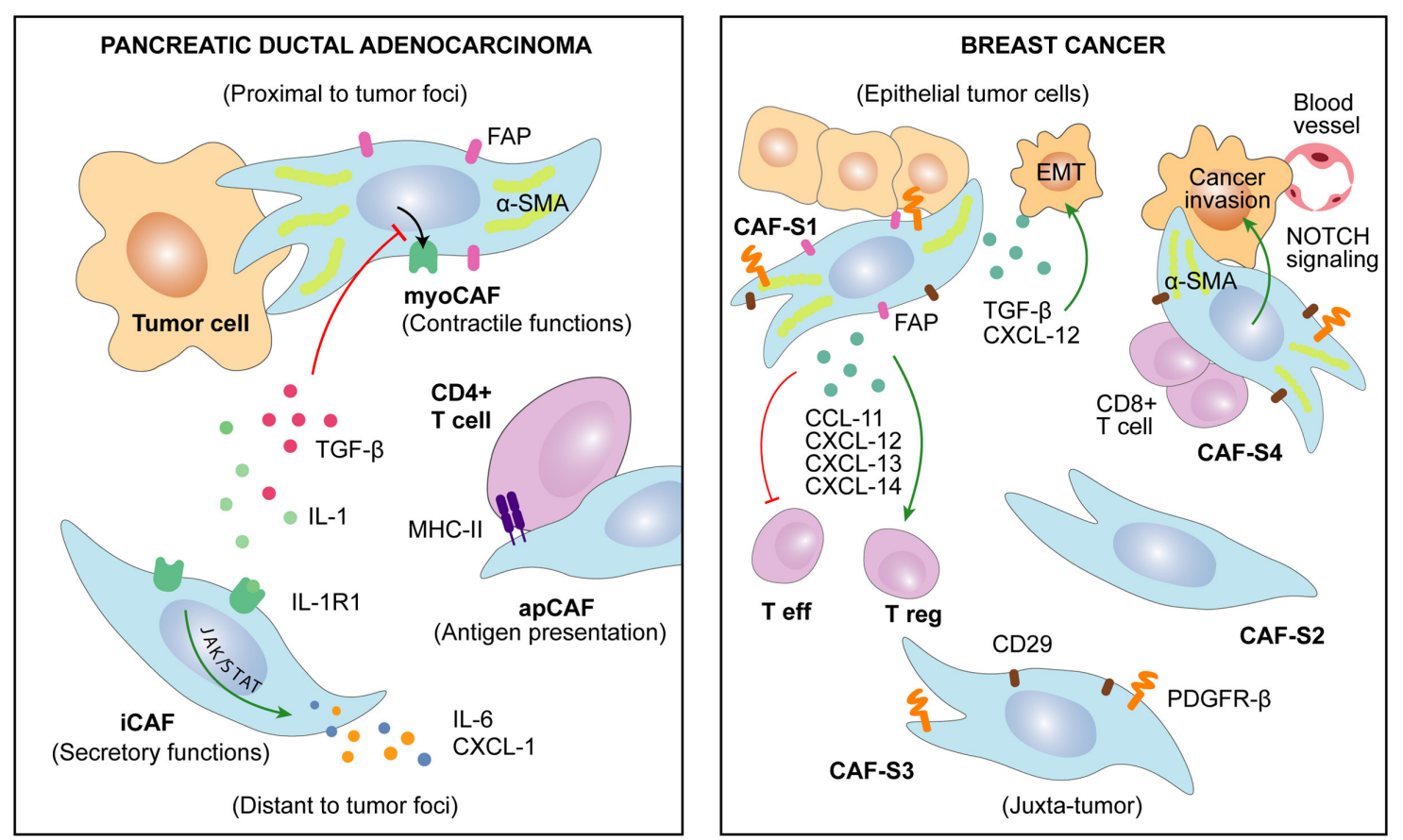

FIGURE 2 | Several CAFs subtypes have been recently described in cancers of distinct origin. CAFs heterogeneity is associated with specific markers and discrete functions. Remarkably, CAFs characteristics may be related to their spatial localization in the tumor.

tumor-promoting phenotype, whereas CAF-S4 seemed to be specialized in NOTCH-dependent contractile and remodeling functions (Pelon et al., 2020). Similarly, CAFs isolated from prostate tumors at different stages revealed that CAFs secretome evolves during PCa development. While localized PCaderived CAFs are characterized by FGF-7 secretion, CAFs from metastatic PCa showed increased levels of matrix metallopeptidase (MMP)-11 and heat shock $70 \mathrm{kDa}$ protein $1 \mathrm{~A}$ (HspA1A) (Eiro et al., 2017).

As previously mentioned, increasing evidence suggests that PCa-derived CAFs secretome is modulated by AR signaling ( $\mathrm{Yu}$ et al., 2013; Cioni et al., 2018). Interestingly, AR expression by CAFs evolves during PCa progression (Olapade-Olaopa et al., 1999; Gevaert et al., 2018). Indeed, metastatic PCa and castration resistance $\mathrm{PCa}$ display significantly lower stromal AR expression than localize tumor- and androgen-dependent PCa (Li et al., 2008; Singh et al., 2014). These observations suggest that a temporal regulation of CAFs secretome may occur through the modulation of hormone receptors expression during cancer progression.

Overall, a complex relationship between temporal and spatial influence may instruct CAFs secretome. However, it is still unknown whether tumor progression orchestrates CAFs function and plasticity according to spatial factors or, conversely, distinct CAFs spatial subtypes are modeling tumor dynamics.

\section{Anti-cancer Therapy as a Determinant of CAFs Secretome Chemotherapy}

Several studies have addressed the modulatory effect of standard chemotherapy (CT) on the TME. CT induces shrinkage of cancer cells compartment resulting in an increased representation of stromal cells in residual tumors (Goto et al., 2017). In this context, factors secreted by CAFs after CT may significantly enhance tumor regrowth from residual cancer cells (Hisamitsu et al., 2019). Current evidence points to CT-induced DNA damage being a key mechanism influencing the repertoire of CAF-secreted factors after treatment (Figure 3). Indeed, CAFs support tumor regrowth after DNA damage-mediated NF-кB signaling activation through secretion of WNT-16B (Sun et al., 2012). Alternatively, treatment of lung adenocarcinoma with cisplatin enhances IL-11 secretion by CAFs, which in turn promotes resistance of cancer cells to CT through the STAT-3 signaling pathway (Tao et al., 2016). Of note, CAF-induced IL11/STAT-3 cell-cell survival signaling has been reported in other tumor types (Calon et al., 2012). Thus, CAF-dependent IL-11 resistance mechanism may be of potential relevance in cancers of distinct origin. Similarly, a direct effect of gemcitabine and 5-FU regimen toward a tumor-supportive secretory phenotype of CAFs has been described in PDAC. In that case, higher expression of secreted factors [intercellular adhesion molecule 1 (ICAM-1), IL-6, GM-CSF, IL-8, CXCL-1] upon treatment has 


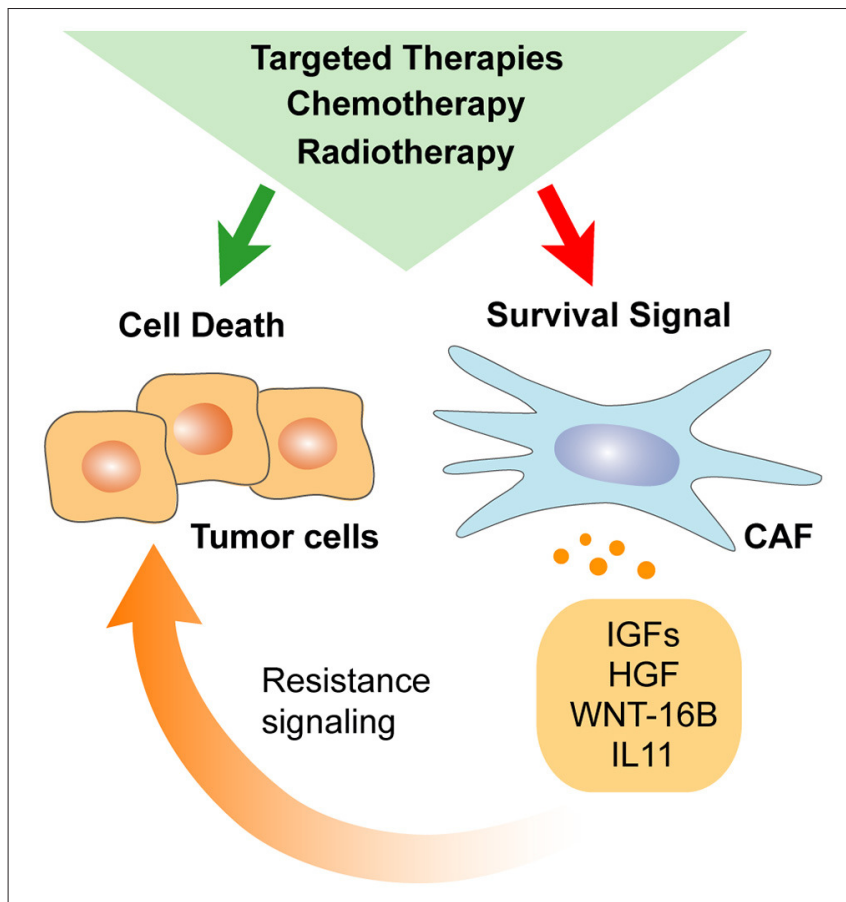

FIGURE 3 | Anti-cancer therapy impacts CAFs secretome. Stromal elements develop their own response to systemic chemotherapy, radiotherapy, and targeted therapy. As a result, CAFs response to treatment may diminish direct anti-cancer drug efficiency by promoting cancer cells self-renewal and survival.

been associated with the activation of stress-associated mitogenactivated protein kinase (MAPK) signaling pathway [Jun Nterminal kinase (JNK) and P38 MAPK] (Toste et al., 2016). Finally, the indirect effect of CT on CAFs secretome may also occur due to the dysregulated crosstalk between cancer cells and CAFs. For instance, Nab-paclitaxel treatment increases CXCL10 expression in pancreatic cancer cells, leading to lower IL6 secretion by CAFs subsequently impairing migration and invasive capabilities of cancer cells (Feng et al., 2018).

\section{Radiotherapy}

Similarly to CT, radiotherapy (RT) has been reported to impact the secretome of CAFs (Figure 3). Rødningen and colleagues showed that ionizing radiation altered the fibroblasts expression of genes involved in ECM remodeling as well as Wnt and IGF signaling to support cancer stemness and resistance to therapy (Rødningen et al., 2005; Wang Z. et al., 2019). Persistent DNA damage, induction of senescence, and TGF-beta pathway activation rather than cellular death are some of the proposed mechanisms modulating CAFs secretome upon RT (Ansems and Span, 2020). Importantly, a vast body of evidence suggests that RT enhances paracrine signaling between fibroblasts and cancer cells through the IGF and TGF-beta pathways (Barker et al., 2015; Tommelein et al., 2018). Promotion of EMT, enhanced cancer stemness properties, and increased resistance to therapy are among the various effects exerted by RT-activated CAFs (Arshad et al., 2015; Barker et al., 2015). For instance, IGF-1 activates the IGF-1R/AKT/mTOR survival pathway in CRC, and
CXCL-12 promotes EMT and invasion in pancreatic cancer (Li D. et al., 2016; Tommelein et al., 2018). Alternatively, RT-activated CAFs may also support intra-tumoral angiogenesis (Hellevik et al., 2013). Interestingly, several studies have reported that the immunoregulation exerted by CAFs remains unaltered after ionizing RT (Hellevik et al., 2013; Gorchs et al., 2015; Berzaghi et al., 2019). Thus, combination with immune-targeted therapies may be an attractive clinical approach for RT-treated patients.

\section{Targeted Therapy}

Originally designed to be specific to cancer cells, targeted therapies may also produce a range of undesirable off-target effects on stromal cells and particularly on CAFs secretome. For instance, specific secretion of HGF and neuregulin (NRG)-1 by fibroblasts upon exposure to vemurafenib -a BRAF inhibitorwas reported in melanoma (Fedorenko et al., 2015). Of note, the activation of MET by HGF has been suggested as a potential mechanism of acquired tyrosine kinase inhibitor (TKI) resistance to gefitinib in epidermal growth factor receptor (EGFR)-mutant non-small cell lung cancer (NSCLC) (Yano et al., 2008) and to vemurafenib itself in BRAF-mutant melanoma (Wilson et al., 2012). In PCa, HGF and NRG-1 have been identified as noncell-autonomous drivers of antiandrogen resistance. In this setting, NRG-1/epidermal growth factor receptor 3 (HER-3) signaling axis blockade demonstrated promising tumor growth suppression (Zhang Z. et al., 2020). More recently, Hirata and colleagues reported alternative CAF-induced resistance to BRAF inhibition. In this setting, BRAF inhibitor reprograms CAFs by enhancing platelet-derived growth factor receptor (PDGFR) activity, thus increasing ECM production -thrombospondin (THBS) $-1 / 2$, tenascin C (TNC), or POSTN, among other matrix components- and stiffness to potentiate cancer cells tolerance to treatment (Hirata et al., 2015). These data illustrate how CAFs functions can be affected even by targeted therapies to enable the emergence of resistance to treatment.

\section{Epigenetic Regulation of CAFs Secretome}

CAF phenotype may be driven by epigenetic deregulation rather than by somatic mutations (Qiu et al., 2008; Bianchi-Frias et al., 2016; Pidsley et al., 2018). DNA methylation, histone modifications, chromatin remodeling, and non-coding RNAmicro RNA (miRNA) and long non-coding RNA (lncRNA)-are the well-described molecular mechanisms behind the epigenetic CAF reprogramming and have been thoroughly reviewed elsewhere (Marks et al., 2016; Melissari et al., 2020; Pan and Zheng, 2020). Interestingly, several studies support the hypothesis that an epigenetic switch would initiate the activation process leading to a stable CAF cell state with tumor-supportive secretory phenotype (Albrengues et al., 2015; Kalluri, 2016).

For instance, multiple genes coding for secreted factors, such as IL-1a, CCL-5, and CCL-26; show differential hypomethylation patterns in CAFs and are consequently overexpressed in pancreatic cancer. In this case, paracrine lactate secreted by PDAC cells leads to ten-eleven translocation (TET) enzyme activation triggering the epigenomic reprogramming (Bhagat et al., 2019). Remarkably, different epigenetic mechanisms can merge into the same signaling cascade as happening 
for the STAT-3 pathway. Indeed, SOCS-1 methylation and downregulation in PDAC-associated CAFs enhance STAT-3induced IGF-1 expression (Xiao et al., 2016) to promote the survival and proliferation of pancreatic cancer cells (Kopantzev et al., 2017). Alternatively, LIF-induced methylation of Shp-1 promoter abrogates its expression leading to a STAT-3-mediated CAF pro-invasive phenotype (Albrengues et al., 2015).

In conclusion, in the absence of genomic mutations, epigenetic alterations may be seen as key determinants of CAF phenotype and could become promising targets for cancer treatment. Importantly, several clinical trials are currently exploring the benefits of DNA methylation therapies in solid tumors including colorectal (NCT01896856), pancreatic (NCT03264404), or prostate cancer (NCT03572387). Even though cancer cells are the intended target, the abovementioned data suggest a potential effect of DNA methylation therapies over CAFs that will need to be carefully assessed in treated patients.

\section{CAFS SECRETOME AS DETERMINANT OF TUMOR DEVELOPMENT \\ Cancer Cells Self-Renewal}

A vast body of evidence indicates that CAFs secretome may contribute to tumor progression by enhancing cancer stemness (Figure 4). Indeed, CAF-secreted IGF-2 as well as IL-6 and IL8 produced by CD-10+ GPR-77+ CAFs are promoting cancer stemness and tumor formation in lung cancer (Chen et al., 2014; Su et al., 2018). Similarly, PCa-derived CAFs with decreased expression of AR promote stemness in cancer cells through IFN$\gamma$ and M-CSF secretion (Liao et al., 2017). Importantly, cancer stemness induced by CAF-secreted factors may involve different pathways. For instance, PI3K/AKT pathway activation drives the progression of anal squamous cell carcinoma through IGF2 secretion by the PDGFRB + CAFs population (Cacheux et al., 2019). Similarly, IGF-2-secreting CAFs promote tumor regrowth and decreased latency after primary resection in CRC (Unger et al., 2017). Alternatively, NOTCH signaling may be triggered by CAF-derived CCL-2 to induce stem cell features as observed in BC cells (Tsuyada et al., 2012). Finally, WNT signaling activation by CAF-secreted HGF in colorectal adenocarcinomas or by CAFsecreted POSTN in head and neck squamous cell carcinoma and $\mathrm{BC}$ cells may also promote cancer stemness and further metastatic initiation (Vermeulen et al., 2010; Malanchi et al., 2011; Yu et al., 2018).

In addition to cytokine-driven signaling, cancer cells selfrenewal and aggressiveness may also depend on metabolic cues originating from the TME (reviewed in Reina-Campos et al., 2017; Li et al., 2020). Specifically, CAFs originating lactate and glutamine production as well as autophagic alanine secretion are sustaining cancer cells metabolism, stemness, and progression to metastasis (Fiaschi et al., 2012; Curry et al., 2013; Sousa et al., 2016; Yang L. et al., 2016). The specific mechanisms enabling CAFs to deliver distinct nutrients to cancer cells are being explored. However, CAFs response to the surrounding constraints, such as the epigenetic reprogramming induced by chronic hypoxia, is likely to play a relevant role in metabolic reprogramming of CAFs (Becker et al., 2020).

\section{Metastatic Cancer Cells Spreading}

As mentioned above, CAF-secreted factors may also drive cancer progression by enhancing the metastatic potential of cancer cells (Figure 4). For instance, while TGF-beta activates different genetic programs in a wide range of stroma cells, the main contributor to its pro-tumorigenic influence seems to be an autocrine loop maintaining the secretion of prometastatic factors by CAFs (Calon et al., 2012). In addition, CAF-secreted TGF-beta promotes paracrine reprogramming of epithelial cancer cells by inducing EMT in tumors of distinct origin (Zhuang et al., 2015). In CRC, TGF-beta induces IL13 expression in fibroblasts, and subsequent TGF-beta/IL-13 synergy activates an EMT program in epithelial cells (Scharl et al., 2013). Alternatively, Calon and colleagues described TGF-betaactivated CAFs secreting IL-6 and IL-11 leading to enhanced STAT-3-dependent survival and spreading of metastatic CRC cells (Calon et al., 2012). Similar observations were made in gastric cancer where CAF-secreted IL-6 induced EMT and metastasis through STAT-3 pathway activation (Wu et al., 2017). Alternatively, CAF-secreted vascular cell adhesion protein (VCAM)-1 has been shown to stimulate lung cancer cells migration and invasion (Zhou et al., 2020).

Besides their autocrine and paracrine activities regulating progression to metastasis, CAFs-secreted factors may also support cancer spreading by influencing ECM deposition at both the primary and metastatic sites. For example, Chakravarthy and colleagues described that TGF-beta-activated CAFs could induce the expression of large ECM components related to cancer progression (Chakravarthy et al., 2018). In this regard, TGFbeta-activated CAFs may secrete POSTN in order to increase proliferation, motility, and invasive properties in head and neck cancer (HNC) cells (Qin et al., 2016). Similarly, CAF-secreted POSTN may also promote tumor progression in CRC through YAP/TAZ activation in cancer cells (Ma et al., 2020). Of note, Deng and colleagues showed that the YAP-activated $\mathrm{Wnt} / \beta$ catenin pathway promotes colon tumorigenesis (Deng et al., 2018). Hence, the overall data suggest a complex paracrine regulation of the Wnt pathway in cancer cells by TGF-betaactivated CAFs through POSTN secretion and YAP activation in order to enhance tumor progression and metastasis formation.

\section{Immunomodulation}

Somewhat contradictory evidences of CAFs immunoregulatory functions have been described during cancer progression (Figure 4). While increased abundance of CAFs clearly predicts immune exclusion and immunotherapy failure, a complete depletion of CAFs was associated with decreased intra-tumoral immune infiltration (Özdemir et al., 2014; Chakravarthy et al., 2018). One reason explaining opposite functions of CAFs in modulating immune infiltration may reside in the fact that different CAFs subpopulations with distinct properties are coexisting inside the tumor. For example, among the four CAF subsets identified in BC, only CAF-S1 subtype characterized by high FAP expression promoted immunosuppression by secreting 


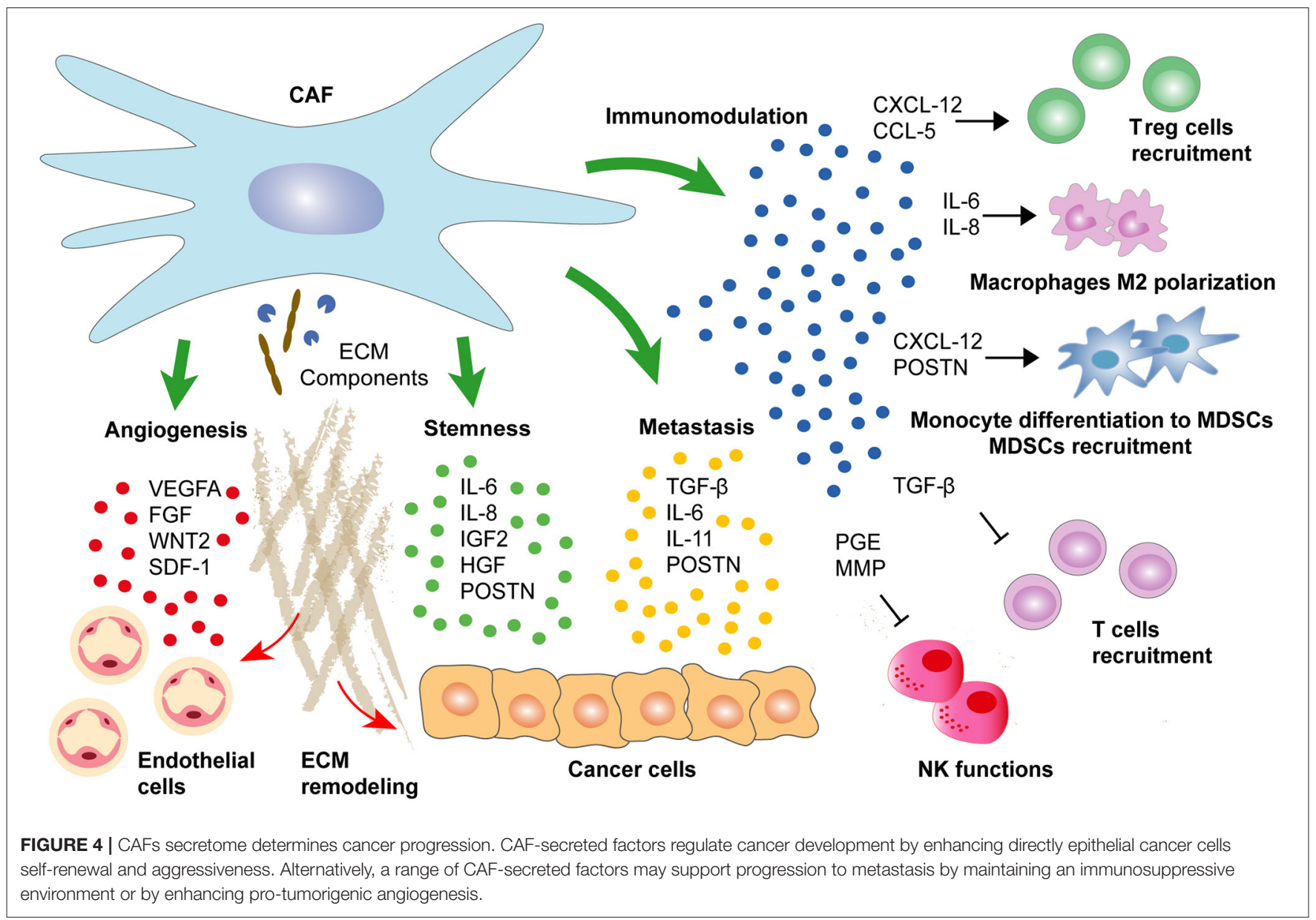

CXCL-12 and enhancing immunosuppressive T regulatory cells $\left(\mathrm{T}_{\mathrm{reg}}\right)$ capacity to block $\mathrm{T}$ effector cells proliferation (Costa et al., 2018). Importantly, FAP + CAFs are also the main producers of CXCL-12 in PDAC, and their specific depletion increases immunological control over tumor growth (Kraman et al., 2010; Feig et al., 2013). In this setting, the decreased expression of CXCL-12 leads to intra-tumoral T cell accumulation, which in turn synergizes with immuno- or chemotherapy to reduce cancer cells abundance (Feig et al., 2013; Sherman et al., 2014).

In addition to CXCL-12, a wide range of CAFproduced chemokines has been associated with tumor immunosuppression. For example, CAF-secreted CCL-5 induces CD4+CD25+ $\mathrm{T}_{\text {reg }}$ cells in BC (Tan et al., 2011; Costa et al., 2018). Notably, CCL-5 dependent $\mathrm{T}_{\text {reg }}$ cells recruitment was associated with lung metastasis in BC mouse model (Tan et al., 2011). CAFs also participate in immunosuppressive myeloid cell recruitment and differentiation by secreting SDF-1 to attract monocytes and to induce their differentiation into myeloid-derived suppressor cells (MDSCs) contributing to cancer immune evasion (Gabrilovich and Nagaraj, 2009; Deng et al., 2017). Alternatively, Wang and colleagues showed that CAF-secreted POSTN promoted MDSCs infiltration to establish a pre-metastatic niche during breast tumor metastasis through AKT and STAT-3 pathway activation (Wang Z. et al., 2016).
Similarly, FAP + CAF-secreted CCL-2 mediates STAT-3 pathway activation in MDSC to promote liver tumor growth and to suppress $\mathrm{T}$ cells proliferation during colorectal carcinogenesis (Chun et al., 2015; Yang et al., 2016). Alternatively, CAF-secreted IL-6 and IL-8 may promote monocytes differentiation into M2 macrophages and further recruitment in the tumor to diminish natural killer (NK) cells cytotoxicity against CRC cells (Cho et al., 2018; Zhang et al., 2019). Finally, CAFs may directly interfere with NK anti-tumoral functions through prostaglandin E2 (PGE2) secretion or MMPs production decreasing NK receptor ligands expression in tumor cells, thus reducing NK receptor-dependent cytotoxic activity (Balsamo et al., 2009; Ziani et al., 2017).

As mentioned earlier, CAFs are major producers of TGFbeta, a key contributor to tumor immunosuppression (Calon et al., 2015; Batlle and Massagué, 2019). For instance, TGF-beta produced by CAFs was correlated with $\mathrm{CD} 8+\mathrm{T}$ cells exclusion, which in turn has been associated with resistance to antiPD-L1 antibody-based immune checkpoint inhibitor therapy (Mariathasan et al., 2018). In this context, TGF-beta pathway blockade through TGF-beta receptor (TGFBR)-1 inhibition or TGF-beta blocking antibody enabled $\mathrm{T}$ cells infiltration into the tumor, restoring the anti-tumor immunity induced by the anti-PD-L1 antibody in BC and CRC pre-clinical models 
(Mariathasan et al., 2018; Tauriello et al., 2018). In contrast, TGFBR-2 deletion in BC induces MDSCs recruitment to the TME, reducing $\mathrm{T}$ cell proliferation and activation (Yang et al., 2008). Interestingly, TGFBR-2 deletion has been associated with the increased expression of stromal TGF-beta leading to MDSCs recruitment of indifferent cancers including HNC or PCa (Lu et al., 2006; Franco et al., 2011). These data suggest that the genetic ablation of TGFBR-2 enhances the secondary activation of TGF-beta that may indirectly promote intra-tumoral immunosuppression.

\section{Angiogenesis}

Neovascularization is an important process during tumorigenesis. Interestingly, CAFs are the main source of VEGF-A, the most potent pro-angiogenic factor, which binds to its cognate VEGF receptor (VEGFR)-2 expressed on endothelial cells (Figure 4) (Fukumura et al., 1998; Apte et al., 2019). Noma and colleagues showed that TGF-beta pathway activation in CAFs was essential to induce VEGF secretion (Noma et al., 2008). In addition, Sánchez-Elsner and colleagues demonstrated a synergistic cooperation between SMADs and hypoxia-inducible factor (HIF)-1 alpha proteins to drive VEGF expression, suggesting a potential link between TGF-beta pathway and hypoxia to promote tumor angiogenesis (SánchezElsner et al., 2001). Nevertheless, there is controversial evidence about the role of TGF-beta in tumor angiogenesis suggesting a differential expression of TGF-beta ligands during different phases of angiogenesis (Pardali et al., 2010). For instance, Liu and colleagues showed that TGFBR-1 inhibitor and VEGF synergistically induced tumor angiogenesis through $\alpha 5$-integrin upregulation (Liu et al., 2009). In contrast, TGF-beta-TGFBR-1 signaling has been involved in the promotion of $\mathrm{BC}$ angiogenesis through MMP-9 upregulation and through CAF-secreted TGF-beta and SDF-1 in HCCs (Safina et al., 2007; Yang J. et al., 2016).

In addition to promoting VEGF-dependent angiogenesis, CAFs may enhance tumor angiogenesis through additional paracrine signaling between stromal and cancer cells (Orimo et al., 2005; Unterleuthner et al., 2020). For instance, CAFderived CXCL-12 leads to CXCL- 8 secretion by PDAC cells inducing new vessel formation by endothelial cells (Matsuo et al., 2009). Alternatively, CAF-secreted galectin1 induces VEGF-A production by $\mathrm{BC}$ cells to promote tumor angiogenesis (Tang et al., 2016). FGF has also been recognized as a potent pro-angiogenic factor involved in tumor angiogenesis (Compagni et al., 2000). Correspondingly, Pietras and colleagues demonstrated that cervical carcinoma-derived CAFs are secreting FGF-7 and FGF-2, inducing both epithelial proliferation and tumor angiogenesis (Pietras et al., 2008).

Finally, CAFs not only are directly promoting tumor angiogenesis by secreting pro-angiogenic factors but also act indirectly by participating in ECM remodeling (Figure 4) (De Palma et al., 2017). For example, CAFs may support vascularization through biomechanical activity and ECM stiffness promoted by MMP activity (Bordeleau et al., 2017; Sewell-Loftin et al., 2017). Importantly, CAFs are the most important suppliers of ECM-associated proteins essential to vascular formation including TNC production resulting in pro-angiogenic paracrine signaling (Newman et al., 2011; Rupp et al., 2016).

\section{Resistance to Anti-cancer Therapy}

In addition to modulating tumor progression, CAFs secretome may also promote resistance to systemic and targeted therapies. For instance, CAF-secreted SDF-1 upregulates the expression of special AT-rich sequence-binding protein-1 (SATB-1) in pancreatic cancer cells, which not only sustains pancreatic tumor growth but also mediates gemcitabine resistance (Wei et al., 2018). Furthermore, CAF-derived IGF-1 and IGF-2 induce CT resistance in pancreatic cancer (Ireland et al., 2016). IGF-2 also increases insulin receptor/IGF 1 receptor (IGF1R) axis activation in cancer cells to enhance resistance to anti-EGFR-targeted therapy in cholangiocarcinoma (Vaquero et al., 2018). In the same line, fibroblast-secreted HGF activates both the MAPK and $\mathrm{PI} 3 \mathrm{~K} / \mathrm{AKT}$ pathways contributing to BRAF-targeted therapies' primary resistance in melanoma and in a subset of colorectal and glioblastoma cancer cells (Straussman et al., 2012).

Regarding hormonotherapy, CAFs-secreted factors contribute to estrogen receptor alpha (ER- $\alpha)$ phosphorylation in BC cells, thereby promoting tamoxifen resistance (Pontiggia et al., 2012). In addition, $\mathrm{Li}$ and colleagues reported that letrozole, an aromatase inhibitor lowering estrogen production, had opposite functional effects on CAFs secretome (Li K. et al., 2016). Letrozole reduces CCL-2, CCL-5, and CXCL-1 expression in CAFs, possibly contributing to its efficacy against BC cells. Conversely, letrozole also increases CAFs secretion of POSTN, a factor involved in BC progression and metastasis (Kyutoku et al., 2011; Li K. et al., 2016). In PCa, Zhang and colleagues, described that CAF-secreted NRG-1 activates the HER-3 signaling pathway leading to resistance to antiandrogen therapy (Zhang Z. et al., 2020). Notably, NRG-1 expression in PCa-derived CAFs is increased after antiandrogen therapy that may contribute to potentiate resistance to treatment (Zhang Z. et al., 2020).

Consequently, the presence in the tumor of a range of secreted factors involved in resistance to therapy may be the result of CAFs' own response to anti-cancer treatment. Indeed, CT induces senescence-associated secretory phenotype in fibroblasts, typically characterized by the increased secretion of cytokines, chemokines, and growth factors previously associated with tumor progression and treatment resistance (Demaria et al., 2017). More specifically, Sun and colleagues demonstrated that primary prostate fibroblasts increased WNT-16B expression in response to CT. In this setting, WNT-16B enhanced prostate tumor growth and diminished CT cytotoxicity against cancer cells (Sun et al., 2012). Finally, previously mentioned IL-11 secreted by CAFs upon cisplatin-based CT induced STAT-3 pathway activation and chemoresistance in lung cancer cells (Tao et al., 2016).

\section{PROGNOSTIC AND PREDICTIVE VALUE OF CAFS SECRETOME}

The identification of tumor features predicting prognosis, risk of relapse, and benefit from treatment is absolutely essential 
for clinical decision-making in oncology. In this sense, a better understanding of the TME has provided multiple prognostic and diagnostic biomarkers in cancers of distinct origin (Bremnes et al., 2011). For instance, CAFs biomarkers (Ha et al., 2014; Dourado et al., 2018), tumor:stroma ratio quantification (Kemi et al., 2018; Vangangelt et al., 2018), and stromal gene expression profiling (Finak et al., 2008; Frings et al., 2013; Calon et al., 2015) are powerful tools predicting clinical outcome. However, addressing the exclusive impact of CAFs secretome on cancer prognosis remains a major challenge, and to our knowledge, there is no example of CAF-secreted biomarkers currently applied to the clinical setting.

Cytokines and chemokines have been proposed as prognostic factors in different types of cancer. Yet, their pleiotropic nature and multiple cellular origin as well as their distinct releasing patterns make their use as biomarkers especially challenging. Circulating IL-6 has been associated with cancer progression and poor prognosis in melanoma, BC, and gastrointestinal tumors, among others (Salgado et al., 2003; Hoejberg et al., 2012; Vainer et al., 2018), but only few studies have assessed IL-6 cellular origin. In bladder cancer patients for instance, CAF-derived IL-6 and ACTA-2 ( $\alpha$ SMA coding gene) coupregulation correlated with poor survival (Goulet et al., 2019). In esophageal adenocarcinoma, although IL-6 serum levels did not correlate with patients' outcome, the expression of ADAM12, a surrogate marker for IL-6-producing CAFs, predicted poor prognosis after neoadjuvant chemoradiation (Ebbing et al., 2019). CXCL chemokines are additional examples of promising prognosis biomarkers associated with CAFs functions. Indeed, CAF-derived CXCL-14 expression was correlated with shorter recurrence-free survival in estrogen receptor negative, triple negative, and basal-like BC (Sjöberg et al., 2016), as well as in additional tumor types (reviewed in Westrich et al., 2020). Similarly, CXCL- 1 and CXCL- 8 positivity in CAFs was significantly associated with poor prognosis in gastric cancer patients (Naito et al., 2019), whereas CXCL-8,-10, and-11 CAFs expression correlated with resistance to neoadjuvant $\mathrm{CT}$ and poor prognosis in BC (Xu et al., 2020).

As previously mentioned, CAFs-secreted growth factors, such as HGF or IGFs, are involved in resistance to targeted therapy and may be of use to predict response to treatment. Indeed, HGF expression was correlated with innate resistance to BRAF inhibition, and increased HGF plasma levels predicted worse overall survival (OS) and progression-free survival (PFS) in BRAF-mutant melanoma patients (Straussman et al., 2012; Wilson et al., 2012). Alternatively, CAF-secreted IGF-binding proteins have been proposed as a potential therapeutic target and prognostic biomarker in pancreatic cancer and other tumor types (Thomas and Radhakrishnan, 2020).

Additional CAFs-secreted proteins, such as VCAM-1, THBS2 , and POSTN, involved in cancer progression were recently evaluated as potential actionable biomarkers. In lung cancer, the soluble fraction of VCAM-1 predicted relapse and lower OS, whereas high POSTN expression was associated with shorter PFS in ovarian cancer patients (Ryner et al., 2015; Zhou et al., 2020). Of note, a recent meta-analysis confirmed the value of POSTN as a biomarker predicting poor outcome in different solid tumors
(Yang et al., 2020). Finally, increased THBS-2 predicted decreased OS in CRC patients (Wang X. et al., 2016).

CAF-derived exosomes transferring miRNA (Au Yeung et al., 2016; Fang et al., 2019; Qin et al., 2019) and lncRNA (Qu et al., 2016) to tumor cells have been reported to promote treatment resistance in different tumor types and were also evaluated as potential predictive biomarkers. In this context, serum detection of plasma exosomal miR-196a levels correlated with tumor size, lymph node metastasis, advanced tumor stage, and poor OS while accurately discriminating chemoresistant and sensitive patients in HNC (Qin et al., 2019). Of note, suppressing or interfering with CAF-derived exosomes transference to cancer cells has been proposed as a novel therapeutic approach (Li et al., 2017).

Similarly to soluble factors, many ECM-related products are contributing to the predictive power of stromal-originating gene signatures (Andriani et al., 2018; Yuzhalin et al., 2018; Jiang et al., 2019). ECM remodeling enzymes, such as MMPs and tissue inhibitors of MMP (TIMP), which are not exclusively but mainly released by CAFs, have also been suggested to predict cancer progression and response to treatment (Liu et al., 2019). Among them, Eiró et al. assessed the potential influence over patients' prognosis of TIMP-2 expression by CAFs at the tumor center and the invasive front of early stage BC. TIMP-2 resulted to be a potent poor outcome predictor at both locations (Eiró et al., 2015). Many members of the MMP family promoting tumor invasion through ECM degradation are also impacting cancer prognosis. For instance, increased MMP-1 expression by CAFs was associated with high risk of relapse in stage II CRC, and CAFs expression of MMP-9, -11 , and -13 correlated with shorter relapse-free survival in BC (González et al., 2009; Eiro et al., 2019). Remarkably, the relevance of MMPs for prognosis might be cancer specific, as illustrated by MMP-2, which predicts poor OS and PFS in NSCLC but associates with better survival in patients with high grade BC (Leinonen et al., 2008; Niemiec et al., 2013).

Along this line, other CAF-secreted ECM components, such as collagens, have been recently recognized as important contributors to cancer progression and as potential liquid biopsy biomarkers in different tumor types (Giussani et al., 2019). Serum level of PRO-C3 -a biomarker of collagen III production- is a promising example predicting poor OS in PDAC patients and may be a non-invasive actionable biomarker for desmoplasia-targeting therapies (Willumsen et al., 2019). Interestingly and probably due to TGF-beta capacity to stimulate collagens production by CAFs, serum levels of collagen fragments have been associated with response to TGF-beta-targeted therapy (Nissen et al., 2019).

Overall, these exciting findings are calling for further validation of CAF-derived biomarkers in order to improve the standard of care and decision-making in oncology. However, it is worth noting that methodological variability will be especially relevant when transferring biomarkers from bench to bedside. Indeed, evaluating either a single or a panel of factors through distinct techniques may complicate the validation of CAFs secretome-based prognostic and predictive tools in the clinical setting (Paulsson and Micke, 2014). Spatial and temporal heterogeneity (see the Determinants of CAFs Secretome section) 
may be an additional issue that could be overcome by liquid biopsy, a non-invasive method allowing real-time evaluation of CAF-secreted biomarkers circulating in the bloodstream (Herrera et al., 2019).

\section{CAF-SECRETED FACTORS AS A THERAPEUTIC TARGET}

\section{Targeting the CAFs Secretome Regulating Cancer Cells Proliferation}

Since CAFs complete depletion or blockade of fibroblastrich tumor stroma formation resulted in decreased antitumor immune infiltration and more aggressive tumors, recent strategies have rather focused on the regulation of CAFs originating paracrine and autocrine signaling (Özdemir et al., 2014; Rhim et al., 2014). For instance, CAFs reprogramming by vitamin $\mathrm{A}$ and vitamin $\mathrm{D}$ was shown to inhibit tumor-supportive secretome associated with cancer progression (Froeling et al., 2011; Sherman et al., 2014). Remarkably, gemcitabine and either vitamin $\mathrm{A}$ or vitamin $\mathrm{D}$ regimen resulted in significant tumor burden reduction in PDAC pre-clinical models (Sherman et al., 2014; Carapuça et al., 2016). Hence, a phase II trial is currently evaluating the combination of CT and vitamin D in PDAC patients (NCT03415854). Yet, a previous phase II trial did not show any survival benefit with high doses of vitamin D3 compared with standard doses in combination with CT in metastatic CRC patients (Ng et al., 2019).

Importantly, vitamin $\mathrm{A}$ and vitamin $\mathrm{D}$ reprograming strategies are both associated with TGF-beta -a key autocrine and paracrine mediator of CAFs signaling- pathway inhibition. Indeed, vitamin $\mathrm{D}$ receptor ligands decrease fibroblast activation by TGF-beta (Ding et al., 2013), whereas all-trans retinoic acid (ATRA) -the active metabolite of vitamin A- inhibits the fibroblasts capacity to release active TGF-beta, thus impeding autocrine TGF-beta activation (Sarper et al., 2016). Of note, ATRA reprogramed fibroblasts are in addition reducing Wnt $-\beta$ catenin signaling in the surrounding cancer cells through SFRP-4 secretion (Froeling et al., 2011).

TGF-beta has emerged as a potential therapeutic target in oncology. Notably, TGF-beta inhibitor in combination with gemcitabine improved the OS in locally advanced and metastatic PDAC patients (Melisi et al., 2018). A phase I/II trial is currently testing the ability of TGF-beta inhibitor to restore the sensitivity to CT in patients with TGF-beta-activated program in metastatic CRC resistant to CT (NCT03470350). The analysis of the TGFbeta-activated program in CAFs provided several additional therapeutic targets. Among them, IL- 6 and IL-11 are secreted interleukins activating STAT-3-dependent survival and spreading of metastatic CRC cancer cells (Calon et al., 2012). IL-11 or IL6 inhibitors displayed potent anti-cancer activity in pre-clinical models of cancer of distinct origins (Coward et al., 2011; Putoczki et al., 2013; Song et al., 2014). Siltuximab, an IL-6 inhibitor, did not show benefit as monotherapy in CT-pretreated castrationresistance PCa patients (Dorff et al., 2010). However, additional IL-6 pathway inhibitors are currently tested in combination with CT in patients with breast (NCT03135171), pancreatic
(NCT04258150, NCT02767557), or liver cancer (NCT04338685). Among CAF-secreted molecules, ECM components have also raised special interest as therapeutic targets. Yet, clinical trials failed to demonstrate the clinical benefit from COL-3, MMP-2, and MMP-9 inhibitors in patients (Chu et al., 2007). Similarly, PEGPH20, a PEGylated recombinant human hyaluronidase, did not add benefit to standard CT in PDAC patients (Tempero et al., 2020).

Off-target effects and indirect resistance to treatment involving CAFs functions may explain the lack of benefit of current stroma-targeting therapies. For example, Casanovas and colleagues described that VEGFR blockade induces tumor hypoxia and paradoxically triggers pro-angiogenic factors production, such as FGF family members (Casanovas et al., 2005). Likewise, CAFs derived from anti-VEGF-resistant tumors are secreting PDGF-C in order to reactivate tumor angiogenesis (Crawford et al., 2009). A potential solution may come from multi-targeted therapies, such as nintedanib, a triple angiokinase inhibitor blocking VEGFR, FGFR, and PDGFR. Nintedanib reduces the CAFs expression of IL-6, IL-8, VEGF, and VCAM1 as well as OPN and showed important clinical benefit in combination with CT in NSCLC patients (Hilberg et al., 2008; Reck et al., 2014; Yamanaka et al., 2020).

\section{Overcoming CAFs-Induced Immunosuppression}

Several preclinical studies have recently underscored the relevance of TGFBR-1 targeting in order to activate an antitumor immune response. TGFBR-1 inhibitor (galunisertib) and anti-PD-L1 combination treatment increased intra-tumoral $\mathrm{T}$ cell infiltration and activation, thereby promoting a potent anti-tumor response in CRC and BC pre-clinical models. Characteristically, this effect was associated with a reduction of fibroblasts activation and an increased anti-tumor immune genes expression (Holmgaard et al., 2018; Mariathasan et al., 2018; Tauriello et al., 2018). Curiously, anti-PD-L1 treatment alone enhanced the expression of TGF-beta activated CAFs biomarkers, suggesting that TGF-beta pathway inhibition is essential to enhance anti-PD-L1 therapy (Holmgaard et al., 2018). In this context, two phase I trials are being conducted to evaluate the benefit of galunisertib in combination with immune checkpoint inhibitors (anti-PD-1, anti-PD-L1) in refractory metastatic cancer patients (NCT02423343, NCT02734160). In contrast, Zhao and colleagues showed that another TGFBR-1 inhibitor (TEW-7197) failed to increase anti-PD-L1 treatment efficacy in melanoma mouse model. TEW-7197 promoted fibroblasts proliferation and diminished PD-L1 expression in cancer cells through MMP-9 secretion by CAFs. Interestingly, the authors reported increased TGFBR-2 expression upon treatment (Zhao et al., 2018). In this context, previously mentioned TGFBR2-induced secondary activation of TGF-beta could potentially contribute to CAFs activation and to combination treatment failure (Lu et al., 2006; Franco et al., 2011).

Bintrafusp alfa, a bi-functional fusion protein composed of an anti-PD-L1 antibody and a TGF-beta "trap", was recently designed to potentiate immune checkpoint and 
TGF-beta inhibitors regimen. Bintrafusp alfa induces tumor regression and decreased spontaneous metastasis in a CRC mouse model by activating $\mathrm{CD} 8+\mathrm{T}$ cells and $\mathrm{NK}$ cells while abrogating CAFs activation in the tumor (Lan et al., 2018). Clinical benefit of bintrafusp alfa is currently under evaluation in several cancer patients' trials including NSCLC (NCT03840902), BC (NCT03579472), HNSCC (NCT04247282), and CRC (NCT03436563).

Remarkably, previously mentioned ATRA-mediated CAFs reprograming increases $\mathrm{T}$ cells infiltration in PDAC while blocking CAFs autocrine TGF-beta activation (Ene-Obong et al., 2013; Sarper et al., 2016). In view of the above-mentioned data on TGF-beta inhibition, pancreatic cancer patients who will be treated with ATRA (NCT04241276) may as well benefit from combination regimen with immune checkpoint inhibitors.

Finally, CAF-secreted factors, such as FN and TNC, have been targeted for antibody-based delivery of immune enhancers specifically to the tumor site in order to concentrate their effect on cancer tissue and decrease treatment-associated toxicity on healthy tissue (Pasche and Neri, 2012). For example, L19TNF and L19-IL-2 immunocytokines conjugate an antibodyrecognizing FN with cytokines (TNF- $\alpha$ and IL-2, respectively) (Neri, 2019). Preclinical data already suggested the robust anti-cancer potential of L19-based immunocytokines (Lieverse et al., 2020), and phase II and III trials are currently testing the clinical benefit of L19-TNF-a and L19-IL-2 in patients with soft tissue sarcoma (NCT03420014) or melanoma (NCT02938299, NCT03567889).

\section{CONCLUSIONS}

From a general perspective, CAFs should be considered as a heterogeneous and dynamic stromal component which evolution to distinct functional subpopulations is paralleling the tumorigenic process. Spatio-temporally regulated factors and crosstalk with other TME components drive this coevolution from local tissue resident fibroblasts and other cell types to distinct CAFs subtypes. Indeed, the intratumoral location effect over CAFs function is determined by spatial distribution of tumor cell-derived factors (Figure 1). Among them, autocrine or paracrine communications and EVs interchange have been described to define CAF phenotypes. However, the influence of other cell populations-infiltrating immune cells, endothelial cells-, and biomechanical stress (ECM stiffness) also differentially distributed within the TME may play an important role in modulating CAFs behavior. Among other potential functions associated with CAFs, there is solid evidence of several well-defined cell sub-specializations with either contractile and ECM remodeling functions or secretory and immunomodulating functions (Figure 2).

The potential role of CAFs secretome for predicting patient's outcome and response to treatment has also been intensively investigated. Overall findings illustrate the potential benefit of using CAFs secretome biomarkers to improve patient's selection and treatment follow-up. Notwithstanding their potential as actionable biomarkers, current knowledge is still mostly providing descriptive information of individual secreted factors but does not advocate for their translation into the clinical setting. Comprehensive -omics analyses are currently being used for an extensive characterization of CAFs secretome in order to discover and validate robust biomarkers and novel targets within the stroma (Principe et al., 2018). In this sense, liquid biopsy appears to be a promising method for real-time evaluation of the different components of CAFs secretome, allowing the detection of CAF-derived soluble factors, CAF-derived exosomes, and even circulating CAFs as potential biomarkers (Herrera et al., 2019).

Recent findings suggest a clear impact of both systemic and targeted anti-cancer therapies upon CAFs secretome that will need to be carefully assessed in view of patients' response to treatment (Figure 3). Understanding the impact of CAFs secretome on treatment resistance after therapy exposure will provide original tools to monitor patient's response. The implementation of clinical criteria evaluating components of the CAFs secretome will help in refining patients' selection for suitable therapies and improve oncological outcomes.

While CAFs contribution over tumor development is still a matter of research, CAFs secretome has already demonstrated its potential as a target for original therapeutic strategies in a wide range of cancers (Figure 4). However, a better understanding of CAFs secretome has also underscored the importance of defining the cell-type specific response to secreted factors. For instance, TGF-beta is a pro-metastatic cytokine currently targeted in multiple clinical trials (NCT04031872, NCT02452008, NCT03834662, NCT04574583). Yet, TGF-beta is also considered as a tumor suppressor due to its cytostatic effect on cancer cells (Akhurst and Hata, 2012). Another example is IL-11, a pro-metastatic factor that can be successfully targeted by IL11 signaling antagonist to reduce cancer progression (Putoczki et al., 2013). Until recently, IL-11 was better known for its capacity to stimulate platelet production, and for decades, cancer patients have been treated with rhIL-11 to overcome CT-induced thrombocytopenia (Isaacs et al., 1997; Cairo et al., 2005; Wu et al., 2012). These findings underscore the importance of carefully assessing every cell-type specific response to secreted factors before therapeutic translation into the clinical setting.

CAFs may not be understood and targeted as a unique family anymore, and a detailed definition of CAFs secretome is still an unmet need. For instance, CAFs and senescent fibroblasts coexisting within the TME are able to secrete equivalent factors. Hence, CAFs secretome and senescence-associated secretory phenotype (SASP) may have overlapping tumor-promoting effects (Sahai et al., 2020).

Different treatment strategies, such as targeting a specific functional subtype of CAFs, reprogramming CAFs backwards to a tumor-suppressor phenotype, or even switching between distinct functional subtypes, are currently being addressed. Along this line, a major challenge in precisely defining CAFs heterogeneity and therapeutically targeting CAFs secretome will reside in a better comprehension of CAFs spatiotemporal evolution during tumor progression.

Overall, it is reasonable to believe that increasing our understanding of CAFs inter- and intra-tumoral heterogeneity will be key to fully grasp CAFs secretome diverseness and potentiate anti-cancer therapy. 


\section{AUTHOR CONTRIBUTIONS}

JL, JM-J, and AC participated to the manuscript preparation and revision (writing, reviewing, discussing, and editing). JB-R made substantial contribution to the manuscript revision. All listed authors approved this manuscript for publication.

\section{REFERENCES}

Acerbi, I., Cassereau, L., Dean, I., Shi, Q., Au, A., Park, C., et al. (2015). Human breast cancer invasion and aggression correlates with ECM stiffening and immune cell infiltration. Integr. Biol. 7, 1120-1134. doi: 10.1039/c5ib00040h

Akhurst, R. J., and Hata, A. (2012). Targeting the TGFbeta signalling pathway in disease. Nat. Rev. Drug Discov. 11, 790-811. doi: 10.1038/nrd3810

Albrengues, J., Bertero, T., Grasset, E., Bonan, S., Maiel, M., Bourget, I., et al. (2015). Epigenetic switch drives the conversion of fibroblasts into proinvasive cancer-associated fibroblasts. Nat. Commun. 6:10204. doi: $10.1038 /$ ncomms10204

Andriani, F., Landoni, E., Mensah, M., Facchinetti, F., Miceli, R., Tagliabue, E., et al. (2018). Diagnostic role of circulating extracellular matrix-related proteins in non-small cell lung cancer 11 medical and health sciences 1112 oncology and carcinogenesis. BMC Cancer 18:899. doi: 10.1186/s12885-018-4772-0

Ansems, M., and Span, P. N. (2020). The tumor microenvironment and radiotherapy response; a central role for cancer-associated fibroblasts. Clin. Transl. Radiat. Oncol. 22, 90-97. doi: 10.1016/j.ctro.2020.04.001

Apte, R. S., Chen, D. S., and Ferrara, N. (2019). VEGF in signaling and disease: beyond discovery and development. Cell 176, 1248-1264. doi: 10.1016/j.cell.2019.01.021

Arshad, A., Deutsch, E., and Vozenin, M. C. (2015). Simultaneous irradiation of fibroblasts and carcinoma cells repress the secretion of soluble factors able to stimulate carcinoma cell migration. PLoS ONE 10:e0115447. doi: 10.1371/journal.pone.0115447

Arwert, E. N., Milford, E. L., Rullan, A., Derzsi, S., Hooper, S., Kato, T., et al. (2020). STING and IRF3 in stromal fibroblasts enable sensing of genomic stress in cancer cells to undermine oncolytic viral therapy. Nat. Cell Biol. 22, 758-766. doi: 10.1038/s41556-020-0527-7

Au Yeung, C. L., Co, N. N., Tsuruga, T., Yeung, T. L., Kwan, S. Y., Leung, C. S., et al. (2016). Exosomal transfer of stroma-derived miR21 confers paclitaxel resistance in ovarian cancer cells through targeting APAF1. Nat. Commun. 7:11150. doi: 10.1038/ncomms11150

Awaji, M., Saxena, S., Wu, L., Prajapati, D. R., Purohit, A., Varney, M. L., et al. (2020). CXCR2 signaling promotes secretory cancer-associated fibroblasts in pancreatic ductal adenocarcinoma. FASEB J. 34, 9405-9418. doi: 10.1096/fj.201902990R

Awaji, M., and Singh, R. K. (2019). Cancer-associated fibroblasts' functional heterogeneity in pancreatic ductal adenocarcinoma. Cancers 11:290. doi: $10.3390 /$ cancers 11030290

Balsamo, M., Scordamaglia, F., Pietra, G., Manzini, C., Cantoni, C., Boitano, M., et al. (2009). Melanoma-associated fibroblasts modulate NK cell phenotype and antitumor cytotoxicity. Proc. Natl. Acad. Sci. U.S.A. 106, 20847-20852. doi: 10.1073/pnas.0906481106

Barker, H. E., Paget, J. T. E. E., Khan, A. A., and Harrington, K. J. (2015). The tumour microenvironment after radiotherapy: mechanisms of resistance and recurrence. Nat. Rev. Cancer 15, 409-425. doi: 10.1038/nrc 3958

Bartoschek, M., Oskolkov, N., Bocci, M., Lövrot, J., Larsson, C., Sommarin, M., et al. (2018). Spatially and functionally distinct subclasses of breast cancerassociated fibroblasts revealed by single cell RNA sequencing. Nat. Commun. 9:5150. doi: 10.1038/s41467-018-07582-3

Batlle, E., and Massagué, J. (2019). Transforming Growth Factor$\beta$ Signaling in Immunity and Cancer. Immunity 50, 924-940. doi: 10.1016/j.immuni.2019.03.024

Bauer, J., Emon, M. A. B., Staudacher, J. J., Thomas, A. L., Zessner-Spitzenberg, J., Mancinelli, G., et al. (2020). Increased stiffness of the tumor microenvironment

\section{ACKNOWLEDGMENTS}

This work has been supported by grants to AC from Instituto de Salud Carlos III with FEDER/FSE co-financing (CP16/00151; PI17/00211), to JL from the Spanish Association against Cancer (AECC; Junior Clinician fellowship).

in colon cancer stimulates cancer associated fibroblast-mediated prometastatic activin A signaling. Sci. Rep. 10:7606. doi: 10.1038/s41598-020-64239-2

Becker, L. M., O'Connell, J. T., Vo, A. P., Cain, M. P., Tampe, D., Bizarro, L., et al. (2020). Epigenetic reprogramming of cancer-associated fibroblasts deregulates glucose metabolism and facilitates progression of breast cancer. Cell Rep. 31:107701. doi: 10.1016/j.celrep.2020.107701

Berdiel-Acer, M., Sanz-Pamplona, R., Calon, A., Cuadras, D., Berenguer, A., Sanjuan, X., et al. (2014). Differences between CAFs and their paired NCF from adjacent colonic mucosa reveal functional heterogeneity of CAFs, providing prognostic information. Mol. Oncol. 8, 1290-1305. doi: 10.1016/j.molonc.2014.04.006

Berzaghi, R., Ahktar, M. A., Islam, A., Pedersen, B. D., Hellevik, T., and Martinez-Zubiaurre, I. (2019). Fibroblast-mediated immunoregulation of macrophage function is maintained after irradiation. Cancers 11:689. doi: 10.3390/cancers 11050689

Bhagat, T. D., Von Ahrens, D., Dawlaty, M., Zou, Y., Baddour, J., Achreja, A., et al. (2019). Lactate-mediated epigenetic reprogramming regulates formation of human pancreatic cancer-associated fibroblasts. Elife 8:e50663. doi: 10.7554/eLife.50663

Bianchi-Frias, D., Basom, R., Delrow, J. J., Coleman, I. M., Dakhova, O., Qu, X., et al. (2016). Genomics cells comprising the prostate cancer microenvironment lack recurrent clonal somatic genomic aberrations. Mol. Cancer Res. 14, 374-384. doi: 10.1158/1541-7786.MCR-15-0330

Biffi, G., Oni, T. E., Spielman, B., Hao, Y., Elyada, E., Park, Y., et al. (2019). Il1-induced Jak/STAT signaling is antagonized by TGF $\beta$ to shape CAF heterogeneity in pancreatic ductal adenocarcinoma. Cancer Discov. 9, 282-301. doi: 10.1158/2159-8290.CD-18-0710

Bordeleau, F., Mason, B. N., Lollis, E. M., Mazzola, M., Zanotelli, M. R., Somasegar, S., et al. (2017). Matrix stiffening promotes a tumor vasculature phenotype. Proc. Natl. Acad. Sci. U.S.A. 114, 492-497. doi: 10.1073/pnas.1613855114

Bordignon, P., Bottoni, G., Xu, X., Popescu, A. S., Truan, Z., Guenova, E., et al. (2019). Dualism of FGF and TGF- $\beta$ signaling in heterogeneous cancerassociated fibroblast activation with ETV1 as a critical determinant. Cell Rep. 28, 2358-2372.e6. doi: 10.1016/j.celrep.2019.07.092

Bremnes, R. M., Dønnem, T., Al-Saad, S., Al-Shibli, K., Andersen, S., Sirera, R., et al. (2011). The role of tumor stroma in cancer progression and prognosis: emphasis on carcinoma-associated fibroblasts and non-small cell lung cancer. J. Thorac. Oncol. 6, 209-217. doi: 10.1097/JTO.0b013e3181f8albd

Cacheux, W., Lièvre, A., Richon, S., Vacher, S., El Alam, E., Briaux, A., et al. (2019). Interaction between IGF2-PI3K axis and cancer-associated-fibroblasts promotes anal squamous carcinogenesis. Int. J. Cancer 145, 1852-1859. doi: $10.1002 /$ ijc. 32178

Cairo, M. S., Davenport, V., Bessmertny, O., Goldman, S. C., Berg, S. L., Kreissman, S. G., et al. (2005). Phase I/II dose escalation study of recombinant human interleukin-11 following ifosfamide, carboplatin and etoposide in children, adolescents and young adults with solid tumours or lymphoma: a clinical, haematological and biological study. Br. J. Haematol. 128, 49-58. doi: 10.1111/j.1365-2141.2004.05281.x

Calon, A., Espinet, E., Palomo-Ponce, S., Tauriello, D. V. F., Iglesias, M., Céspedes, M. V., et al. (2012). Dependency of colorectal cancer on a TGF- $\beta$-driven program in stromal cells for metastasis initiation. Cancer Cell 22, 571-584. doi: 10.1016/j.ccr.2012.08.013

Calon, A., Lonardo, E., Berenguer-Llergo, A., Espinet, E., Hernando-Momblona, X., Iglesias, M., et al. (2015). Stromal gene expression defines poor-prognosis subtypes in colorectal cancer. Nat. Genet. 47, 320-329. doi: 10.1038/ng.3225

Calvo, F., Ege, N., Grande-Garcia, A., Hooper, S., Jenkins, R. P., Chaudhry, S. I., et al. (2013). Mechanotransduction and YAP-dependent matrix remodelling is 
required for the generation and maintenance of cancer-associated fibroblasts. Nat. Cell Biol. 15, 637-646. doi: 10.1038/ncb2756

Calvo, F., Ranftl, R., Hooper, S., Farrugia, A. J., Moeendarbary, E., Bruckbauer, A., et al. (2015). Cdc42EP3/BORG2 and septin network enables mechanotransduction and the emergence of cancer-associated fibroblasts. Cell Rep. 13, 2699-2714. doi: 10.1016/j.celrep.2015.11.052

Cangkrama, M., Wietecha, M., Mathis, N., Okumura, R., Ferrarese, L., Al-Nuaimi, D., et al. (2020). A paracrine activin A-mDia2 axis promotes squamous carcinogenesis via fibroblast reprogramming. EMBO Mol. Med. 12, 1-21. doi: $10.15252 /$ emmm.201911466

Carapuça, E. F., Gemenetzidis, E., Feig, C., Bapiro, T. E., Williams, M. D., Wilson, A. S., et al. (2016). Anti-stromal treatment together with chemotherapy targets multiple signalling pathways in pancreatic adenocarcinoma. J. Pathol. 239, 286-296. doi: 10.1002/path.4727

Casanovas, O., Hicklin, D. J., Bergers, G., and Hanahan, D. (2005). Drug resistance by evasion of antiangiogenic targeting of VEGF signaling in late-stage pancreatic islet tumors. Cancer Cell 8, 299-309. doi: 10.1016/j.ccr.2005.09.005

Chakravarthy, A., Khan, L., Bensler, N. P., Bose, P., and de Carvalho, D. D. (2018). TGF- $\beta$-associated extracellular matrix genes link cancer-associated fibroblasts to immune evasion and immunotherapy failure. Nat. Commun. 9:4692. doi: 10.1038/s41467-018-06654-8

Chen, W. J., Ho, C. C., Chang, Y. L., Chen, H. Y., Lin, C. A., Ling, T. Y., et al. (2014). Cancer-associated fibroblasts regulate the plasticity of lung cancer stemness via paracrine signalling. Nat. Commun. 5:4472. doi: 10.1038/ncomms4472

Cho, H., Seo, Y., Loke, K. M., Kim, S. W., Oh, S. M., Kim, J. H., et al. (2018). Cancerstimulated CAFs enhance monocyte differentiation and protumoral TAM activation via IL6 and GM-CSF secretion. Clin. Cancer Res. 24, 5407-5421. doi: 10.1158/1078-0432.CCR-18-0125

Chu, Q. S. C., Forouzesh, B., Syed, S., Mita, M., Schwartz, G., Copper, J., et al. (2007). A phase II and pharmacological study of the matrix metalloproteinase inhibitor (MMPI) COL-3 in patients with advanced soft tissue sarcomas. Invest. New Drugs 25, 359-367. doi: 10.1007/s10637-006-9031-6

Chun, E., Lavoie, S., Michaud, M., Gallini, C. A., Kim, J., Soucy, G., et al. (2015). CCL2 Promotes colorectal carcinogenesis by enhancing polymorphonuclear myeloid-derived suppressor cell population and function. Cell Rep. 12, 244-257. doi: 10.1016/j.celrep.2015.06.024

Cioni, B., Nevedomskaya, E., Melis, M. H. M., van Burgsteden, J., Stelloo, S., Hodel, E., et al. (2018). Loss of androgen receptor signaling in prostate cancerassociated fibroblasts (CAFs) promotes CCL2- and CXCL8-mediated cancer cell migration. Mol. Oncol. 12, 1308-1323. doi: 10.1002/1878-0261.12327

Clocchiatti, A., Ghosh, S., Procopio, M. G., Mazzeo, L., Bordignon, P., Ostano, P., et al. (2018). Androgen receptor functions as transcriptional repressor of cancer-associated fibroblast activation. J. Clin. Invest. 128, 5465-5478. doi: 10.1172/JCI99159

Compagni, A., Wilgenbus, P., Impagnatiello, M. A., Cotton, M., and Christofori, G. (2000). Fibroblast growth factors are required for efficient tumor angiogenesis. Cancer Res. 60, 7163-7169.

Costa, A., Kieffer, Y., Scholer-Dahirel, A., Pelon, F., Bourachot, B., Cardon, M., et al. (2018). Fibroblast heterogeneity and immunosuppressive environment in human breast cancer. Cancer Cell 33, 463-479.e10. doi: 10.1016/j.ccell.2018.01.011

Coward, J., Kulbe, H., Chakravarty, P., Leader, D., Vassileva, V., Leinster, D. A., et al. (2011). Interleukin-6 as a therapeutic target in human ovarian cancer. Clin. Cancer Res. 17, 6083-6096. doi: 10.1158/1078-0432.CCR-11-0945

Crawford, Y., Kasman, I., Yu, L., Zhong, C., Wu, X., Modrusan, Z., et al. (2009). PDGF-C mediates the angiogenic and tumorigenic properties of fibroblasts associated with tumors refractory to anti-VEGF treatment. Cancer Cell 15, 21-34. doi: 10.1016/j.ccr.2008.12.004

Curry, J. M., Tuluc, M., Whitaker-Menezes, D., Ames, J. A., Anantharaman, A., Butera, A., et al. (2013). Cancer metabolism, stemness and tumor recurrence : MCT1 and MCT4 are functional biomarkers of metabolic symbiosis in head and neck cancer. Cell Cycle 12, 1371-1384. doi: 10.4161/cc.24092

Dai, G., Yao, X., Zhang, Y., Gu, J., Geng, Y., Xue, F., et al. (2018). Colorectal cancer cell-derived exosomes containing miR-10b regulate fibroblast cells via the PI3K/Akt pathway. Bull. Cancer 105, 336-349. doi: 10.1016/j.bulcan.2017.12.009

D'Arcangelo, E., Wu, N. C., Cadavid, J. L., and McGuigan, A. P. (2020). The life cycle of cancer-associated fibroblasts within the tumour stroma and its importance in disease outcome. Br. J. Cancer 122, 931-942. doi: 10.1038/s41416-019-0705-1

Dayalan Naidu, S., and Dinkova-Kostova, A. T. (2017). Regulation of the mammalian heat shock factor 1. FEBS J. 284, 1606-1627. doi: 10.1111/febs.13999

De Palma, M., Biziato, D., and Petrova, T. V. (2017). Microenvironmental regulation of tumour angiogenesis. Nat. Rev. Cancer 17, 457-474. doi: 10.1038/nrc.2017.51

Demaria, M., O'Leary, M. N., Chang, J., Shao, L., Liu, S., Alimirah, F., et al. (2017). Cellular senescence promotes adverse effects of chemotherapy and cancer relapse. Cancer Discov. 7, 165-176. doi: 10.1158/2159-8290.CD-16-0241

Deng, F., Peng, L., Li, Z., Tan, G., Liang, E., Chen, S., et al. (2018). YAP triggers the Wnt/ $\beta$-catenin signalling pathway and promotes enterocyte self-renewal, regeneration and tumorigenesis after DSS-induced injury. Cell Death Dis. 9:153. doi: 10.1038/s41419-017-0244-8

Deng, Y., Cheng, J., Fu, B., Liu, W., Chen, G., Zhang, Q., et al. (2017). Hepatic carcinoma-associated fibroblasts enhance immune suppression by facilitating the generation of myeloid-derived suppressor cells. Oncogene 36, 1090-1101. doi: 10.1038/onc.2016.273

Ding, N., Yu, R. T., Subramaniam, N., Sherman, M. H., Wilson, C., Rao, R., et al. (2013). A vitamin D receptor/SMAD genomic circuit gates hepatic fibrotic response. Cell 153, 601-613. doi: 10.1016/j.cell.2013.03.028

Dorff, T. B., Goldman, B., Pinski, J. K., Mack, P. C., Lara, P. N., van Veldhuizen, P. J., et al. (2010). Clinical and correlative results of SWOG S0354: a phase II trial of CNTO328 (siltuximab), a monoclonal antibody against interleukin-6, in chemotherapy-pretreated patients with castration-resistant prostate cancer. Clin. Cancer Res. 16, 3028-3034. doi: 10.1158/1078-0432.CCR-09-3122

Dörsam, B., Bösl, T., Reiners, K. S., Barnert, S., Schubert, R., Shatnyeva, O., et al. (2018). Hodgkin lymphoma-derived extracellular vesicles change the secretome of fibroblasts toward a CAF phenotype. Front. Immunol. 9:1358. doi: 10.3389/fimmu.2018.01358

Dourado, M. R., Guerra, E. N. S., Salo, T., Lambert, D. W., and Coletta, R. D. (2018). Prognostic value of the immunohistochemical detection of cancerassociated fibroblasts in oral cancer: a systematic review and meta-analysis. J. Oral Pathol. Med. 47, 443-453. doi: 10.1111/jop.12623

Dourado, M. R., Korvala, J., Åström, P., de Oliveira, C. E., Cervigne, N. K., Mofatto, L. S., et al. (2019). Extracellular vesicles derived from cancer-associated fibroblasts induce the migration and invasion of oral squamous cell carcinoma. J. Extracell. Vesicles 8:1578525. doi: 10.1080/20013078.2019.1578525

Ebbing, E. A., van Der Zalm, A. P., Steins, A., Creemers, A., Hermsen, S., Rentenaar, R., et al. (2019). Stromal-derived interleukin 6 drives epithelial-tomesenchymal transition and therapy resistance in esophageal adenocarcinoma. Proc. Natl. Acad. Sci. U.S.A. 116, 2237-2242. doi: 10.1073/pnas.1820459116

Eiro, N., Carrión, J. F., Cid, S., Andicoechea, A., García-Muñiz, J. L., González, L. O., et al. (2019). Toll-like receptor 4 and matrix metalloproteases 11 and 13 as predictors of tumor recurrence and survival in stage II colorectal cancer. Pathol. Oncol. Res. 25, 1589-1597. doi: 10.1007/s12253-019-00611-6

Eiró, N., Fernandez-Garcia, B., Vázquez, J., Delcasar, J. M., González, L. O., and Vizoso, F. J. (2015). A phenotype from tumor stroma based on the expression of metalloproteases and their inhibitors, associated with prognosis in breast cancer. Oncoimmunology 4:e992222. doi: 10.4161/2162402X.2014.992222

Eiro, N., Fernandez-Gomez, J., Sacristán, R., Fernandez-Garcia, B., Lobo, B., Gonzalez-Suarez, J., et al. (2017). Stromal factors involved in human prostate cancer development, progression and castration resistance. J. Cancer Res. Clin. Oncol. 143, 351-359. doi: 10.1007/s00432-016-2284-3

Elyada, E., Bolisetty, M., Laise, P., Flynn, W. F., Courtois, E. T., Burkhart, R. A., et al. (2019). Cross-species single-cell analysis of pancreatic ductal adenocarcinoma reveals antigen-presenting cancer-associated fibroblasts. Cancer Discov. 9, 1102-1123. doi: 10.1158/2159-8290.CD-19-0094

Ene-Obong, A., Clear, A. J., Watt, J., Wang, J., Fatah, R., Riches, J. C., et al. (2013). Activated pancreatic stellate cells sequester CD8+ $\mathrm{T}$ cells to reduce their infiltration of the juxtatumoral compartment of pancreatic ductal adenocarcinoma. Gastroenterology 145, 1121-1132. doi: 10.1053/j.gastro.2013.07.025

Erez, N., Truitt, M., Olson, P., and Hanahan, D. (2010). Cancer-associated fibroblasts are activated in incipient neoplasia to orchestrate tumor-promoting inflammation in an NF-кB-dependent manner. Cancer Cell 17, 135-147. doi: 10.1016/j.ccr.2009.12.041 
Fan, J., Xu, G., Chang, Z., Zhu, L., and Yao, J. (2020). MiR-210 transferred by lung cancer cell-derived exosomes may act as proangiogenic factor in cancerassociated fibroblasts by modulating JAK2/STAT3 pathway. Clin. Sci. 134, 807-825. doi: $10.1042 / C S 20200039$

Fang, T., Lv, H., Lv, G., Li, T., Wang, C., Han, Q., et al. (2018). Tumor-derived exosomal miR-1247-3p induces cancer-associated fibroblast activation to foster lung metastasis of liver cancer. Nat. Commun. 9:191. doi: 10.1038/s41467-017-02583-0

Fang, Y., Zhou, W., Rong, Y., Kuang, T., Xu, X., Wu, W., et al. (2019). Exosomal miRNA-106b from cancer-associated fibroblast promotes gemcitabine resistance in pancreatic cancer. Exp. Cell Res. 383:111543. doi: 10.1016/j.yexcr.2019.111543

Fedorenko, I. V., Wargo, J. A., Flaherty, K. T., Messina, J. L., and Smalley, K. S. M. (2015). BRAF inhibition generates a host-tumor niche that mediates therapeutic escape. J. Invest. Dermatol. 135, 3115-3124. doi: $10.1038 /$ jid.2015.329

Feig, C., Jones, J. O., Kraman, M., Wells, R. J. B., Deonarine, A., Chan, D. S., et al. (2013). Targeting CXCL12 from FAP-expressing carcinoma-associated fibroblasts synergizes with anti-PD-L1 immunotherapy in pancreatic cancer. Proc. Natl. Acad. Sci. U.S.A. 110, 20212-20217. doi: 10.1073/pnas.1320318110

Feng, R., Morine, Y., Ikemoto, T., Imura, S., Iwahashi, S., Saito, Y., et al. (2018). Nab-paclitaxel interrupts cancer-stromal interaction through C-X-C motif chemokine 10-mediated interleukin-6 downregulation in vitro. Cancer Sci. 109, 2509. doi: $10.1111 /$ cas. 13694

Fiaschi, T., Marini, A., Giannoni, E., Taddei, M. L., Gandellini, P., de Donatis, A., et al. (2012). Reciprocal metabolic reprogramming through lactate shuttle coordinately influences tumor-stroma interplay. Cancer Res. 72, 5130-5140. doi: 10.1158/0008-5472.CAN-12-1949

Finak, G., Bertos, N., Pepin, F., Sadekova, S., Souleimanova, M., Zhao, H., et al. (2008). Stromal gene expression predicts clinical outcome in breast cancer. Nat. Med. 14, 518-527. doi: 10.1038/nm1764

Franco, O. E., Jiang, M., Strand, D. W., Peacock, J., Fernandez, S., Jackson, R. S., et al. (2011). Altered TGF- $\beta$ signaling in a subpopulation of human stromal cells promotes prostatic carcinogenesis. Cancer Res. 71, 1272-1281. doi: 10.1158/0008-5472.CAN-10-3142

Frings, O., Augsten, M., Tobin, N. P., Carlson, J., Paulsson, J., Pena, C., et al. (2013). Prognostic significance in breast cancer of a gene signature capturing stromal PDGF signaling. Am. J. Pathol. 182, 2037-2047. doi: 10.1016/j.ajpath.2013.02.018

Froeling, F. E. M., Feig, C., Chelala, C., Dobson, R., Mein, C. E., Tuveson, D. A., et al. (2011). Retinoic acid-induced pancreatic stellate cell quiescence reduces paracrine Wnt $\beta$-catenin signaling to slow tumor progression. Gastroenterology 141, 1486-1497.e14. doi: 10.1053/j.gastro.2011.06.047

Fukumura, D., Xavier, R., Sugiura, T., Chen, Y., Park, E. C., Lu, N., et al. (1998). Tumor induction of VEGF promoter activity in stromal cells. Cell 94, 715-725. doi: 10.1016/S0092-8674(00)81731-6

Gabrilovich, D. I., and Nagaraj, S. (2009). Myeloid-derived suppressor cells as regulators of the immune system. Nat. Rev. Immunol. 9, 162-174. doi: $10.1038 /$ nri2506

Gao, M. Q., Kim, B. G., Kang, S., Choi, Y. P., Park, H., Kang, K. S., et al. (2010). Stromal fibroblasts from the interface zone of human breast carcinomas induce an epithelial-mesenchymal transition-like state in breast cancer cells in vitro. J. Cell Sci. 123, 3507-3514. doi: 10.1242/jcs.072900

Gevaert, T., van Eycke, Y. R., vanden Broeck, T., van Poppel, H., Salmon, I., Rorive, S., et al. (2018). Comparing the expression profiles of steroid hormone receptors and stromal cell markers in prostate cancer at different Gleason scores. Sci. Rep. 8:14326. doi: 10.1038/s41598-018-32711-9

Giussani, M., Triulzi, T., Sozzi, G., and Tagliabue, E. (2019). Tumor extracellular matrix remodeling: new perspectives as a circulating tool in the diagnosis and prognosis of solid tumors. Cells 8:81. doi: 10.3390/cells8020081

Giusti, I., Francesco, M., Di, D’Ascenzo, S., Palmerini, M. G., Macchiarelli, G., Carta, G., et al. (2018). Ovarian cancer-derived extracellular vesicles affect normal human fibroblast behavior. Cancer Biol. Ther. 19:722. doi: $10.1080 / 15384047.2018 .1451286$

González, L. O., Corte, M. D., Junquera, S., González-Fernández, R., del Casar, J. M., García, C., et al. (2009). Expression and prognostic significance of metalloproteases and their inhibitors in luminal $\mathrm{A}$ and basal-like phenotypes of breast carcinoma. Hum. Pathol. 40, 1224-1233. doi: 10.1016/j.humpath.2008.12.022

Gorchs, L., Hellevik, T., Bruun, J. A., Camilio, K. A., Al-Saad, S., Stuge, T. B., et al. (2015). Cancer-associated fibroblasts from lung tumors maintain their immunosuppressive abilities after high-dose irradiation. Front. Oncol. 5:87. doi: 10.3389/fonc.2015.00087

Goto, M., Naito, M., Saruwatari, K., Hisakane, K., Kojima, M., Fujii, S., et al. (2017). The ratio of cancer cells to stroma after induction therapy in the treatment of non-small cell lung cancer. J. Cancer Res. Clin. Oncol. 143, 215-223. doi: 10.1007/s00432-016-2271-8

Goulet, C. R., Champagne, A., Bernard, G., Vandal, D., Chabaud, S., Pouliot, F., et al. (2019). Cancer-associated fibroblasts induce epithelial-mesenchymal transition of bladder cancer cells through paracrine IL-6 signalling. BMC Cancer 19:137. doi: 10.1186/s12885-019-5353-6

Ha, S. Y., Yeo, S.-Y., Xuan, Y., and Kim, S.-H. (2014). The prognostic significance of cancer-associated fibroblasts in esophageal squamous cell carcinoma. PLoS ONE 9:e99955. doi: 10.1371/journal.pone.0099955

Han, L., Lam, E. W. F., and Sun, Y. (2019). Extracellular vesicles in the tumor microenvironment: old stories, but new tales. Mol. Cancer 18, 1-14. doi: 10.1186/s12943-019-0980-8

Hellevik, T., Pettersen, I., Berg, V., Bruun, J., Bartnes, K., Busund, L.-T., et al. (2013). Changes in the secretory profile of NSCLC-associated fibroblasts after ablative radiotherapy: potential impact on angiogenesis and tumor growth. Transl. Oncol. 6:66. doi: 10.1593/tlo.12349

Herrera, M., Galindo-Pumariño, C., García-Barberán, V., and Peña, C. (2019). A snapshot of the tumor microenvironment in colorectal cancer: the liquid biopsy. Int. J. Mol. Sci. 20:6016. doi: 10.3390/ijms20236016

Hilberg, F., Roth, G. J., Krssak, M., Kautschitsch, S., Sommergruber, W., TontschGrunt, U., et al. (2008). BIBF 1120: triple angiokinase inhibitor with sustained receptor blockade and good antitumor efficacy. Cancer Res. 68, 4774-4782. doi: 10.1158/0008-5472.CAN-07-6307

Hirata, E., Girotti, M. R., Viros, A., Hooper, S., Spencer-Dene, B., Matsuda, M., et al. (2015). Intravital imaging reveals how BRAF inhibition generates drugtolerant microenvironments with high integrin $\beta 1 /$ FAK Signaling. Cancer Cell 27, 574-588. doi: 10.1016/j.ccell.2015.03.008

Hisamitsu, S., Miyashita, T., Hashimoto, H., Neri, S., Sugano, M., Nakamura, H., et al. (2019). Interaction between cancer cells and cancer-associated fibroblasts after cisplatin treatment promotes cancer cell regrowth. Hum. Cell 32, 453-464. doi: 10.1007/s13577-019-00275-Z

Hoejberg, L., Bastholt, L., Johansen, J., Christensen, I., Gehl, J., and Schmidt, H. (2012). Serum interleukin-6 as a prognostic biomarker in patients with metastatic melanoma. Melanoma Res. 22. doi: 10.1097/CMR.0b013e3283550aa5

Holmgaard, R. B., Schaer, D. A., Li, Y., Castaneda, S. P., Murphy, M. Y., Xu, $X$., et al. (2018). Targeting the TGF $\beta$ pathway with galunisertib, a TGF $\beta R I$ small molecule inhibitor, promotes anti-tumor immunity leading to durable, complete responses, as monotherapy and in combination with checkpoint blockade. J. Immunother. Cancer 6:47. doi: 10.1186/s40425-018-0356-4

Hu, J. L., Wang, W., Lan, X. L., Zeng, Z. C., Liang, Y. S., Yan, Y. R., et al. (2019). CAFs secreted exosomes promote metastasis and chemotherapy resistance by enhancing cell stemness and epithelial-mesenchymal transition in colorectal cancer. Mol. Cancer 18:91. doi: 10.1186/s12943-019-1019-x

Huan, J., Hornick, N. I., Shurtleff, M. J., Skinner, A. M., Goloviznina, N. A., Roberts, C. T., et al. (2013). RNA trafficking by acute myelogenous leukemia exosomes. Cancer Res. 73, 918-929. doi: 10.1158/0008-5472.CAN-12-2184

Ireland, L., Santos, A., Ahmed, M. S., Rainer, C., Nielsen, S. R., Quaranta, V., et al. (2016). Chemoresistance in pancreatic cancer is driven by stroma-derived insulin-like growth factors. Cancer Res. 76, 6851-6863. doi: 10.1158/0008-5472.CAN-16-1201

Isaacs, C., Robert, N. J., Bailey, F. A., Schuster, M. W., Overmoyer, B., Graham, M., et al. (1997). Randomized placebo-controlled study of recombinant human interleukin-11 to prevent chemotherapy-induced thrombocytopenia in patients with breast cancer receiving dose-intensive cyclophosphamide and doxorubicin. J. Clin. Oncol. 15, 3368-3377. doi: 10.1200/JCO.1997.15.11.3368

Jiang, K., Liu, H., Xie, D., and Xiao, Q. (2019). Differentially expressed genes ASPN, COL1A1, FN1, VCAN and MUC5AC are potential prognostic biomarkers for gastric cancer. Oncol. Lett. 17, 3191-3202. doi: 10.3892/ol.2019.9952 
Kalluri, R. (2016). The biology and function of fibroblasts in cancer. Nat. Rev. Cancer 16, 582-598. doi: 10.1038/nrc.2016.73

Karlan, B. Y., Dering, J., Walsh, C., Orsulic, S., Lester, J., Anderson, L. A., et al. (2014). POSTN/TGFBI-associated stromal signature predicts poor prognosis in serous epithelial ovarian cancer. Gynecol. Oncol. 132, 334-342. doi: 10.1016/j.ygyno.2013.12.021

Kemi, N., Eskuri, M., Herva, A., Leppänen, J., Huhta, H., Helminen, O., et al. (2018). Tumour-stroma ratio and prognosis in gastric adenocarcinoma. Br. J. Cancer 119, 435-439. doi: 10.1038/s41416-018-0202-y

Kojima, Y., Acar, A., Eaton, E. N., Mellody, K. T., Scheel, C., Ben-Porath, I., et al. (2010). Autocrine TGF- $\beta$ and stromal cell-derived factor-1 (SDF-1) signaling drives the evolution of tumor-promoting mammary stromal myofibroblasts. Proc. Natl. Acad. Sci. U.S.A. 107, 20009-20014. doi: 10.1073/pnas.1013805107

Kopantzev, E. P., Grankina, E. V., Kopantseva, M. R., and Sverdlov, E. D. (2017). The IGF-I/IGF-IR signaling system and pancreatic cancer. Mol. Genet. Microbiol. Virol. 32, 131-136. doi: 10.3103/S0891416817030041

Kraman, M., Bambrough, P. J., Arnold, J. N., Roberts, E. W., Magiera, L., Jones, J. O., et al. (2010). Suppression of antitumor immunity by stromal cells expressing fibroblast activation protein-alpha. Science 330, 827-830. doi: 10.1126/science.1195300

Kryza, T., Silva, L. M., Bock, N., Fuhrman-Luck, R. A., Stephens, C. R., Gao, J., et al. (2017). Kallikrein-related peptidase 4 induces cancer-associated fibroblast features in prostate-derived stromal cells. Mol. Oncol. 11, 1307-1329. doi: 10.1002/1878-0261.12075

Kyutoku, M., Taniyama, Y., Katsuragi, N., Shimizu, H., Kunugiza, Y., Iekushi, K., et al. (2011). Role of periostin in cancer progression and metastasis: inhibition of breast cancer progression and metastasis by anti-periostin antibody in a murine model. Int. J. Mol. Med. 28, 181-186. doi: 10.3892/ijmm.2011.712

Lambrechts, D., Wauters, E., Boeckx, B., Aibar, S., Nittner, D., Burton, O., et al. (2018). Phenotype molding of stromal cells in the lung tumor microenvironment. Nat. Med. 24, 1277-1289. doi: 10.1038/s41591-018-0096-5

Lan, Y., Zhang, D., Xu, C., Hance, K. W., Marelli, B., Qi, J., et al. (2018). Enhanced preclinical antitumor activity of M7824, a bifunctional fusion protein simultaneously targeting PD-L1 and TGF-. Sci. Transl. Med. 10:aan5488. doi: 10.1126/scitranslmed.aan5488

Leinonen, T., Pirinen, R., Böhm, J., Johansson, R., and Kosma, V. M. (2008). Increased expression of matrix metalloproteinase-2 (MMP-2) predicts tumour recurrence and unfavourable outcome in non-small cell lung cancer. Histol. Histopathol. 23, 693-700. doi: 10.14670/HH-23.693

Li, J., Eu, J. Q., Kong, L. R., Wang, L., Lim, Y. C., Goh, B. C., et al. (2020). Targeting metabolism in cancer cells and the tumour microenvironment for cancer therapy. Molecules 25:4831. doi: 10.3390/molecules25204831

Li, K., Kang, H., Wang, Y., Hai, T., Rong, G., and Sun, H. (2016). Letrozole-induced functional changes in carcinoma-associated fibroblasts and their influence on breast cancer cell biology. Med. Oncol. 33:64. doi: 10.1007/s12032-016-0779-z

Li, W., Zhang, X., Wang, J., Li, M., Cao, C., Tan, J., et al. (2017). TGF $\beta 1$ in fibroblasts-derived exosomes promotes epithelial-mesenchymal transition of ovarian cancer cells. Oncotarget 8, 96035-96047. doi: 10.18632/oncotarget.21635

Li, Y., Li, C. X., Ye, H., Chen, F., Melamed, J., Peng, Y., et al. (2008). Decrease in stromal androgen receptor associates with androgen-independent disease and promotes prostate cancer cell proliferation and invasion. J. Cell. Mol. Med. 12, 2790-2798. doi: 10.1111/j.1582-4934.2008.00279.x

Li, Z., Zhang, J., Zhou, J., Lu, L., Wang, H., Zhang, G., et al. (2019). Nodal facilitates differentiation of fibroblasts to cancer-associated fibroblasts that support tumor growth in melanoma and colorectal cancer. Cells 8:538. doi: $10.3390 /$ cells 8060538

Li, D., Qu, C., Ning, Z., Wang, H., Zang, K., Zhuang, L., et al. (2016). Radiation promotes epithelial-to-mesenchymal transition and invasion of pancreatic cancer cell by activating carcinoma-associated fibroblasts. Am. J. Cancer Res. $6,2192-2206$

Liao, C. P., Chen, L. Y., Luethy, A., Kim, Y., Kani, K., Macleod, A. R., et al. (2017). Androgen receptor in cancerassociated fibroblasts influences stemness in cancer cells. Endocr. Relat. Cancer 24, 157-170. doi: 10.1530/ERC-16-0138

Lieverse, Y. R. I., Marcus, enne, A., van der Wiel, A. M., van Limbergen, E. J., Theys, J., Yaromina, A., et al. (2020). Human fibronectin extra domain B as a biomarker for targeted therapy in cancer. Mol. Oncol. 14, 1555-1568. doi: $10.1002 / 1878-0261.12705$
Liu, T., Zhou, L., Li, D., Andl, T., and Zhang, Y. (2019). Cancer-associated fibroblasts build and secure the tumor microenvironment. Front. Cell Dev. Biol. 7:60. doi: 10.3389/fcell.2019.00060

Liu, Z., Kobayashi, K., van Dinther, M., van Heiningen, S. H., Valdimarsdottir, G., van Laar, T., et al. (2009). VEGF and inhibitors of TGF $\beta$ type-I receptor kinase synergistically promote blood-vessel formation by inducing $\alpha 5$-integrin expression. J. Cell Sci. 122, 3294-3302. doi: 10.1242/jcs.048942

Lu, S. L., Herrington, H., Reh, D., Weber, S., Bornstein, S., Wang, D., et al. (2006). Loss of transforming growth factor- $\beta$ type II receptor promotes metastatic head-and-neck squamous cell carcinoma. Genes Dev. 20, 1331-1342. doi: 10.1101/gad.1413306

Luo, M., Luo, Y., Mao, N., Huang, G., Teng, C., Wang, H., et al. (2018). Cancerassociated fibroblasts accelerate malignant progression of non-small cell lung cancer via connexin 43-formed unidirectional gap junctional intercellular communication. Cell. Physiol. Biochem. 51, 315-336. doi: 10.1159/000495232

Ma, H., Wang, J., Zhao, X., Wu, T., Huang, Z., Chen, D., et al. (2020). Periostin promotes colorectal tumorigenesis through integrin-FAKSrc pathway-mediated YAP/TAZ activation. Cell Rep. 30, 793-806.e6. doi: $10.1016 /$ j.celrep.2019.12.075

Malanchi, I., Santamaria-Martínez, A., Susanto, E., Peng, H., Lehr, H.-A., Delaloye, J.-F., et al. (2011). Interactions between cancer stem cells and their niche govern metastatic colonization. Nature 481, 85-89. doi: 10.1038/nature10694

Mariathasan, S., Turley, S. J., Nickles, D., Castiglioni, A., Yuen, K., Wang, Y., et al. (2018). TGF $\beta$ attenuates tumour response to PD-L1 blockade by contributing to exclusion of T cells. Nature 554, 544-548. doi: 10.1038/nature25501

Marks, D. L., Olson, R., Lo, and Fernandez-Zapico, M. E. (2016). Epigenetic control of the tumor microenvironment. Epigenomics 8, 1671-1687. doi: 10.2217/epi-2016-0110

Matsuo, Y., Ochi, N., Sawai, H., Yasuda, A., Takahashi, H., Funahashi, H., et al. (2009). CXCL8/IL-8 and CXCL12/SDF-l $\alpha$ co-operatively promote invasiveness and angiogenesis in pancreatic cancer. Int. J. Cancer 124, 853-861. doi: $10.1002 /$ ijc. 24040

Melisi, D., Garcia-Carbonero, R., Macarulla, T., Pezet, D., Deplanque, G., Fuchs, M., et al. (2018). Galunisertib plus gemcitabine vs. gemcitabine for first-line treatment of patients with unresectable pancreatic cancer. Br. J. Cancer 119, 1208-1214. doi: 10.1038/s41416-018-0246-z

Melissari, M.-T., Chalkidi, N., Sarris, M. E., and Koliaraki, V. (2020). Fibroblast reprogramming in gastrointestinal cancer. Front. Cell Dev. Biol. 8:630. doi: $10.3389 /$ fcell.2020.00630

Mitsui, Y., Tomonobu, N., Watanabe, M., Kinoshita, R., Sumardika, I. W., Youyi, C., et al. (2019). Upregulation of mobility in pancreatic cancer cells by secreted S100A11 through activation of surrounding fibroblasts. Oncol. Res. 27, 945-956. doi: 10.3727/096504019X155554087 84978

Naito, Y., Yamamoto, Y., Sakamoto, N., Shimomura, I., Kogure, A., Kumazaki, M., et al. (2019). Cancer extracellular vesicles contribute to stromal heterogeneity by inducing chemokines in cancer-associated fibroblasts. Oncogene 38, 5566-5579. doi: 10.1038/s41388-019-0832-4

Neri, D. (2019). Antibody-cytokine fusions: versatile products for the modulation of anticancer immunity. Cancer Immunol. Res. 7, 348-354. doi: 10.1158/2326-6066.CIR-18-0622

Neuzillet, C., Tijeras-Raballand, A., Ragulan, C., Cros, J., Patil, Y., Martinet, M., et al. (2019). Inter- and intra-tumoural heterogeneity in cancer-associated fibroblasts of human pancreatic ductal adenocarcinoma. J. Pathol. 248, 51-65. doi: $10.1002 /$ path. 5224

Newman, A. C., Nakatsu, M. N., Chou, W., Gershon, P. D., and Hughes, C. C. W. (2011). The requirement for fibroblasts in angiogenesis: fibroblast-derived matrix proteins are essential for endothelial cell lumen formation. Mol. Biol. Cell 22, 3791-3800. doi: 10.1091/mbc.e11-05-0393

Ng, K., Nimeiri, H. S., McCleary, N. J., Abrams, T. A., Yurgelun, M. B., Cleary, J. M., et al. (2019). Effect of high-dose vs standard-dose vitamin D3 supplementation on progression-free survival among patients with advanced or metastatic colorectal cancer: the SUNSHINE randomized clinical trial. JAMA 321, 1370-1379. doi: 10.1001/jama.2019.2402

Nielsen, S. N., Quaranta, V., Linford, A., Emeagi, P., Rainer, C., Santos, A., et al. (2016). Macrophage-secreted granulin supports pancreatic cancer metastasis by inducing liver fibrosis. Nat. Cell Biol. 18, 549-560. doi: 10.1038/ ncb3340 
Niemiec, J., Adamczyk, A., Małecki, K., Ambicka, A., and Ryś, J. (2013). Tumor grade and matrix metalloproteinase 2 expression in stromal fibroblasts help to stratify the high-risk group of patients with early breast cancer identified on the basis of St gallen recommendations. Clin. Breast Cancer 13, 119-128. doi: $10.1016 /$ j.clbc.2012.12.005

Nissen, N. I., Karsdal, M., and Willumsen, N. (2019). Collagens and cancer associated fibroblasts in the reactive stroma and its relation to cancer biology. J. Exp. Clin. Cancer Res. 38:115. doi: 10.1186/s13046-019-1110-6

Noma, K., Smalley, K. S. M., Lioni, M., Naomoto, Y., Tanaka, N., El-Deiry, W., et al. (2008). The essential role of fibroblasts in esophageal squamous cell carcinoma-induced angiogenesis. Gastroenterology 134, 1981-1993. doi: $10.1053 /$ j.gastro.2008.02.061

Öhlund, D., Handly-Santana, A., Biffi, G., Elyada, E., Almeida, A. S., PonzSarvise, M., et al. (2017). Distinct populations of inflammatory fibroblasts and myofibroblasts in pancreatic cancer. J. Exp. Med. 214, 579-596. doi: $10.1084 /$ jem. 20162024

Olapade-Olaopa, E. O., MacKay, E. H., Taub, N. A., Sandhu, D. P. S., Terry, T. R., and Habib, F. K. (1999). Malignant transformation of human prostatic epithelium is associated with the loss of androgen receptor immunoreactivity in the surrounding stroma. Clin. Cancer Res. 5, 569-576.

Orimo, A., Gupta, P. B., Sgroi, D. C., Arenzana-Seisdedos, F., Delaunay, T., Naeem, R., et al. (2005). Stromal fibroblasts present in invasive human breast carcinomas promote tumor growth and angiogenesis through elevated SDF1/CXCL12 secretion. Cell 121, 335-348. doi: 10.1016/j.cell.2005.02.034

Özdemir, B. C., Pentcheva-Hoang, T., Carstens, J. L., Zheng, X., Wu, C. C., Simpson, T. R., et al. (2014). Depletion of carcinoma-associated fibroblasts and fibrosis induces immunosuppression and accelerates pancreas cancer with reduced survival. Cancer Cell 25, 719-734. doi: 10.1016/j.ccr.2014.04.005

Pan, X., and Zheng, L. (2020). Epigenetics in modulating immune functions of stromal and immune cells in the tumor microenvironment. Cell. Mol. Immunol. 17, 940-953. doi: 10.1038/s41423-020-0505-9

Pardali, E., Goumans, M. J., and ten Dijke, P. (2010). Signaling by members of the TGF- $\beta$ family in vascular morphogenesis and disease. Trends Cell Biol. 20, 556-567. doi: 10.1016/j.tcb.2010.06.006

Pasche, N., and Neri, D. (2012). Immunocytokines: a novel class of potent armed antibodies. Drug Discov. Today 17, 583-590. doi: 10.1016/j.drudis.2012.01.007

Paulsson, J., and Micke, P. (2014). Prognostic relevance of cancerassociated fibroblasts in human cancer. Semin. Cancer Biol. 25, 61-68. doi: 10.1016/j.semcancer.2014.02.006

Pelon, F., Bourachot, B., Kieffer, Y., Magagna, I., Mermet-Meillon, F., Bonnet, I., et al. (2020). Cancer-associated fibroblast heterogeneity in axillary lymph nodes drives metastases in breast cancer through complementary mechanisms. Nat. Commun. 11:404. doi: 10.1038/s41467-019-14134-w

Pidsley, R., Lawrence, M. G., Zotenko, E., Niranjan, B., Statham, A., Song, J., et al. (2018). Enduring epigenetic landmarks define the cancer microenvironment. Genome Res. 28, 625-638. doi: 10.1101/gr.229070.117

Pietras, K., Pahler, J., Bergers, G., and Hanahan, D. (2008). Functions of paracrine PDGF signaling in the proangiogenic tumor stroma revealed by pharmacological targeting. PLoS Med. 5:e19. doi: 10.1371/journal.pmed.0050019

Pontiggia, O., Sampayo, R., Raffo, D., Motter, A., Xu, R., Bissell, M. J., et al. (2012). The tumor microenvironment modulates tamoxifen resistance in breast cancer: a role for soluble stromal factors and fibronectin through $\beta 1$ integrin. Breast Cancer Res. Treat. 133, 459-471. doi: 10.1007/s10549-011-1766-x

Principe, S., Mejia-Guerrero, S., Ignatchenko, V., Sinha, A., Ignatchenko, A., Shi, W., et al. (2018). Proteomic analysis of cancer-associated fibroblasts reveals a paracrine role for MFAP5 in human oral tongue squamous cell carcinoma. J. Proteome Res. 17, 2045-2059. doi: 10.1021/acs.jproteome.7b00925

Putoczki, T. L., Thiem, S., Loving, A., Busuttil, R. A., Wilson, N. J., Ziegler, P. K., et al. (2013). Interleukin-11 is the dominant Il-6 family cytokine during gastrointestinal tumorigenesis and can be targeted therapeutically. Cancer Cell 24, 257-271. doi: 10.1016/j.ccr.2013.06.017

Qin, X., Guo, H., Wang, X., Zhu, X., Yan, M., Wang, X., et al. (2019). Exosomal miR-196a derived from cancer-associated fibroblasts confers cisplatin resistance in head and neck cancer through targeting CDKN1B and ING5. Genome Biol. 20:12. doi: 10.1186/s13059-018-1604-0
Qin, X., Yan, M., Zhang, J., Wang, X., Shen, Z., Lv, Z., et al. (2016). TGFß3-mediated induction of Periostin facilitates head and neck cancer growth and is associated with metastasis. Sci. Rep. 6:20587. doi: 10.1038/srep20587

Qiu, W., Hu, M., Sridhar, A., Opeskin, K., Fox, S., Shipitsin, M., et al. (2008). No evidence of clonal somatic genetic alterations in cancer-associated fibroblasts from human breast and ovarian carcinomas. Nat. Genet. 40, 650-655. doi: $10.1038 /$ ng. 117

Qu, L., Ding, J., Chen, C., Wu, Z. J., Liu, B., Gao, Y., et al. (2016). Exosome-t lncARSR promotes sunitinib resistance in renal cancer by acting as a competing endogenous RNA. Cancer Cell 29, 653-668. doi: 10.1016/j.ccell.2016.03.004

Rai, A., Greening, D. W., Chen, M., Xu, R., Ji, H., and Simpson, R. J. (2019). Exosomes derived from human primary and metastatic colorectal cancer cells contribute to functional heterogeneity of activated fibroblasts by reprogramming their proteome. Proteomics 19:e800148. doi: 10.1002/pmic.201800148

Reck, M., Kaiser, R., Mellemgaard, A., Douillard, J. Y., Orlov, S., Krzakowski, M., et al. (2014). Docetaxel plus nintedanib versus docetaxel plus placebo in patients with previously treated non-small-cell lung cancer (LUME-Lung 1): a phase 3, double-blind, randomised controlled trial. Lancet Oncol. 15, 143-155. doi: 10.1016/S1470-2045(13)70586-2

Reina-Campos, M., Moscat, J., and Diaz-Meco, M. (2017). Metabolism shapes the tumor microenvironment. Curr. Opin. Cell Biol. 48, 47-53. doi: $10.1016 /$ j.ceb.2017.05.006

Rhim, A. D., Oberstein, P. E., Thomas, D. H., Mirek, E. T., Palermo, C. F., Sastra, S. A., et al. (2014). Stromal elements act to restrain, rather than support, pancreatic ductal adenocarcinoma. Cancer Cell 25, 735-747. doi: 10.1016/..ccr.2014.04.021

Rødningen, O., Overgaard, J., Alsner, J., Hastie, T., and Børresen-Dale, A. L. (2005). Microarray analysis of the transcriptional responseto single or multiple doses of ionizing radiation in human subcutaneous fibroblasts. Radiother. Oncol. 77, 231-240. doi: 10.1016/j.radonc.2005.09.020

Rothenberger, N. J., Somasundaram, A., and Stabile, L. P. (2018). The role of the estrogen pathway in the tumor microenvironment. Int. J. Mol. Sci. 19:611. doi: $10.3390 /$ ijms 19020611

Rupp, T., Langlois, B., Koczorowska, M. M., Radwanska, A., Sun, Z., Hussenet, T., et al. (2016). Tenascin-C orchestrates glioblastoma angiogenesis by modulation of pro- and anti-angiogenic signaling. Cell Rep. 17, 2607-2619. doi: 10.1016/j.celrep.2016.11.012

Ryner, L., Guan, Y., Firestein, R., Xiao, Y., Choi, Y., Rabe, C., et al. (2015). Upregulation of periostin and reactive stroma is associated with primary chemoresistance and predicts clinical outcomes in epithelial ovarian cancer. Clin. Cancer Res. 21, 2941-2951. doi: 10.1158/1078-0432.CCR14-3111

Safina, A., Vandette, E., and Bakin, A. V. (2007). ALK5 promotes tumor angiogenesis by upregulating matrix metalloproteinase- 9 in tumor cells. Oncogene 26, 2407-2422. doi: 10.1038/sj.onc.1210046

Sahai, E., Astsaturov, I., Cukierman, E., DeNardo, D. G., Egeblad, M., Evans, R. M., et al. (2020). A framework for advancing our understanding of cancer-associated fibroblasts. Nat. Rev. Cancer 20, 174-186. doi: 10.1038/s41568-019-0238-1

Salgado, R., Junius, S., Benoy, I., van Dam, P., Vermeulen, P., Van Marck, E., et al. (2003). Circulating interleukin-6 predicts survival in patients with metastatic breast cancer. Int. J. Cancer 103, 642-646. doi: 10.1002/ijc.10833

Sánchez-Elsner, T., Botella, L. M., Velasco, B., Corb,í, A., Attisano, L., and Bernabéu, C. (2001). Synergistic cooperation between hypoxia and transforming growth factor- $\beta$ pathways on human vascular endothelial growth factor gene expression. J. Biol. Chem. 276, 38527-38535. doi: $10.1074 /$ jbc.M104536200

Sansone, P., Savini, C., Kurelac, I., Chang, Q., Amato, L. B., Strillacci, A., et al. (2017). Packaging and transfer of mitochondrial DNA via exosomes regulate escape from dormancy in hormonal therapy-resistant breast cancer. Proc. Natl. Acad. Sci. U.S.A. 114, E9066-E9075. doi: 10.1073/pnas.170486 2114

Sarper, M., Cortes, E., Lieberthal, T. J., and Del Río Hernández, A. (2016). ATRA modulates mechanical activation of TGF- $\beta$ by pancreatic stellate cells. Sci. Rep. 6:27639. doi: 10.1038/srep27639 
Savardashtaki, A., Shabaninejad, Z., Movahedpour, A., Sahebnasagh, R., Mirzaei, H., and Hamblin, M. R. (2019). MiRNAs derived from cancerassociated fibroblasts in colorectal cancer. Epigenomics 11, 1627-1645. doi: 10.2217/epi-2019-0110

Scharl, M., Frei, S., Pesch, T., Kellermeier, S., Arikkat, J., Frei, P., et al. (2013). Interleukin-13 and transforming growth factor $\beta$ synergise in the pathogenesis of human intestinal fistulae. Gut 62, 63-72. doi: 10.1136/gutjnl-2011-300498

Scherz-Shouval, R., Santagata, S., Mendillo, M. L., Sholl, L. M., Ben-Aharon, I., Beck, A. H., et al. (2014). The reprogramming of tumor stroma by HSF1 is a potent enabler of malignancy. Cell 158, 564-578. doi: 10.1016/j.cell.2014.05.045

Sewell-Loftin, M. K., Bayer, S. V. H., Crist, E., Hughes, T., Joison, S. M., Longmore, G. D., et al. (2017). Cancer-associated fibroblasts support vascular growth through mechanical force. Sci. Rep. 7:12574. doi: 10.1038/s41598-017-13006-x

Sherman, M. H., Yu, R. T., Engle, D. D., Ding, N., Atkins, A. R., Tiriac, H., et al. (2014). Vitamin D receptor-mediated stromal reprogramming suppresses pancreatitis and enhances pancreatic cancer therapy. Cell 159, 80-93. doi: 10.1016/j.cell.2014.08.007

Singh, M., Jha, R., Melamed, J., Shapiro, E., Hayward, S. W., and Lee, P. (2014). Stromal androgen receptor in prostate development and cancer. Am. J. Pathol. 184, 2598-2607. doi: 10.1016/j.ajpath.2014.06.022

Sjöberg, E., Augsten, M., Bergh, J., Jirström, K., and Östman, A. (2016). Expression of the chemokine CXCL14 in the tumour stroma is an independent marker of survival in breast cancer. Br. J. Cancer 114, 1117-1124. doi: 10.1038/bjc.2016.104

Song, L., Smith, M. A., Doshi, P., Sasser, K., Fulp, W., Altiok, S., et al. (2014). Antitumor efficacy of the anti-interleukin-6 (IL-6) antibody siltuximab in mouse xenograft models of lung cancer. J. Thorac. Oncol. 9, 974-982. doi: $10.1097 / J T O .0000000000000193$

Sousa, C. M., Biancur, D. E., Wang, X., Halbrook, C. J., Sherman, M. H., Zhang, L., et al. (2016). Pancreatic stellate cells support tumour metabolism through autophagic alanine secretion. Nature 536, 479-483. doi: 10.1038/nature19084

Straussman, R., Morikawa, T., Shee, K., Barzily-Rokni, M., Qian, Z. R., Du, J., et al. (2012). Tumour micro-environment elicits innate resistance to RAF inhibitors through HGF secretion. Nature 487, 500-504. doi: 10.1038/nature11183

Su, S., Chen, J., Yao, H., Liu, J., Yu, S., Lao, L., et al. (2018). CD10+GPR77+ cancer-associated fibroblasts promote cancer formation and chemoresistance by sustaining cancer stemness. Cell 172, 841-856.e16. doi: 10.1016/j.cell.2018.01.009

Sun, L. P., Xu, K., Cui, J., Yuan, D. Y., Zou, B., Li, J., et al. (2019). Cancerassociated fibroblast-derived exosomal miR-382-5p promotes the migration and invasion of oral squamous cell carcinoma. Oncol. Rep. 42, 1319-1328. doi: 10.3892/or.2019.7255

Sun, Y., Campisi, J., Higano, C., Beer, T. M., Porter, P., Coleman, I., et al. (2012). Treatment-induced damage to the tumor microenvironment promotes prostate cancer therapy resistance through WNT16B. Nat. Med. 18, 1359-1368. doi: $10.1038 / \mathrm{nm} .2890$

Tan, W., Zhang, W., Strasner, A., Grivennikov, S., Cheng, J. Q., Hoffman, R. M., et al. (2011). Tumour-infiltrating regulatory T cells stimulate mammary cancermetastasis through RANKL-RANK signalling. Nature 470, 548-553. doi: 10.1038/nature09707

Tang, D., Gao, J., Wang, S., Ye, N., Chong, Y., Huang, Y., et al. (2016). Cancerassociated fibroblasts promote angiogenesis in gastric cancer through galectin-1 expression. Tumor Biol. 37, 1889-1899. doi: 10.1007/s13277-015-3942-9

Tanner, M. J., Welliver, R. C., Chen, M., Shtutman, M., Godoy, A., Smith, G., et al. (2011). Effects of androgen receptor and androgen on gene expression in prostate stromal fibroblasts and paracrine signaling to prostate cancer cells. PLoS ONE 6:e0016027. doi: 10.1371/journal.pone.0016027

Tao, L., Huang, G., Wang, R., Pan, Y., He, Z., Chu, X., et al. (2016). Cancerassociated fibroblasts treated with cisplatin facilitates chemoresistance of lung adenocarcinoma through IL-11/IL-11R/STAT3 signaling pathway. Sci. Rep. 6:38408. doi: 10.1038/srep38408

Tauriello, D. V. F., Palomo-Ponce, S., Stork, D., BerenguerLlergo, A., Badia-Ramentol, J., Iglesias, M., et al. (2018). TGF $\beta$ drives immune evasion in genetically reconstituted colon cancer metastasis. Nature 554, 538-543. doi: 10.1038/nature2 5492
Tempero, M. A., van Cutsem, E., Sigal, D., Oh, D.-Y., Fazio, N., Macarulla T., et al. (2020). HALO 109-301: a randomized, double-blind, placebocontrolled, phase 3 study of pegvorhyaluronidase alfa (PEGPH20) + nabpaclitaxel/gemcitabine (AG) in patients (pts) with previously untreated hyaluronan (HA)-high metastatic pancreatic ductal adenocarcinom. J. Clin. Oncol. 38:638. doi: 10.1200/JCO.2020.38.4_suppl.638

Thomas, D., and Radhakrishnan, P. (2020). Role of tumor and stroma-derived IGF/IGFBPS in pancreatic cancer. Cancers 12:1228. doi: 10.3390/cancers 12051228

Tommelein, J., de Vlieghere, E., Verset, L., Melsens, E., Leenders, J., Descamps, B., et al. (2018). Radiotherapy-activated cancer-associated fibroblasts promote tumor progression through paracrine IGF1R activation. Cancer Res. 78, 659-670. doi: 10.1158/0008-5472.CAN-17-0524

Toste, P. A., Nguyen, A. H., Kadera, B. E., Duong, M., Wu, N., Gawlas, I., et al. (2016). Chemotherapy-induced inflammatory gene signature and protumorigenic phenotype in pancreatic CAFs via stress-Associated MAPK. Mol. Cancer Res. 14, 437-447. doi: 10.1158/1541-7786.MCR-15-0348

Tsuyada, A., Chow, A., Wu, J., Somlo, G., Chu, P., Loera, S., et al. (2012). CCL2 mediates cross-talk between cancer cells and stromal fibroblasts that regulates breast cancer stem cells. Cancer Res. 72, 2768-2779. doi: 10.1158/0008-5472.CAN-11-3567

Umakoshi, M., Takahashi, S., Itoh, G., Kuriyama, S., Sasaki, Y., Yanagihara, K., et al. (2019). Macrophage-mediated transfer of cancer-derived components to stromal cells contributes to establishment of a pro-tumor microenvironment. Oncogene 38, 2162-2176. doi: 10.1038/s41388-018-0564-x

Unger, C., Kramer, N., Unterleuthner, D., Scherzer, M., Burian, A., Rudisch, A., et al. (2017). Stromal-derived IGF2 promotes colon cancer progression via paracrine and autocrine mechanisms. Oncogene 36, 5341-5355. doi: 10.1038/onc.2017.116

Unterleuthner, D., Neuhold, P., Schwarz, K., Janker, L., Neuditschko, B., Nivarthi, H., et al. (2020). Cancer-associated fibroblast-derived WNT2 increases tumor angiogenesis in colon cancer. Angiogenesis 23, 159-177. doi: 10.1007/s10456-019-09688-8

Vainer, N., Dehlendorff, C., and Johansen, J. S. (2018). Systematic literature review of IL-6 as a biomarker or treatment target in patients with gastric, bile duct, pancreatic and colorectal cancer. Oncotarget 9:29820. doi: 10.18632/oncotarget.25661

van Niel, G., D'Angelo, G., and Raposo, G. (2018). Shedding light on the cell biology of extracellular vesicles. Nat. Rev. Mol. Cell Biol. 19, 213-228. doi: $10.1038 / \mathrm{nrm} .2017 .125$

Vangangelt, K. M. H., Tollenaar, L. S. A., van Pelt, G. W., de Kruijf, E. M., Dekker, T. J. A., Kuppen, P. J. K., et al. (2018). The prognostic value of tumor-stroma ratio in tumor-positive axillary lymph nodes of breast cancer patients. Int. J. Cancer 143, 3194-3200. doi: 10.1002/ijc.31658

Vaquero, J., Lobe, C., Tahraoui, S., Claperon, A., Mergey, M., Merabtene, F., et al. (2018). The IgF2/IR/IGF1R pathway in tumor cells and myofibroblasts mediates resistance to EGFR inhibition in cholangiocarcinoma. Clin. Cancer Res. 24, 4282-4296. doi: 10.1158/1078-0432.CCR-17-3725

Vermeulen, L., de Sousa E Melo, F., van Der Heijden, M., Cameron, K., de Jong, J. H., Borovski, T., et al. (2010). Wnt activity defines colon cancer stem cells and is regulated by the microenvironment. Nat. Cell Biol. 12, 468-476. doi: $10.1038 /$ ncb2048

Vivacqua, A., Muoio, M. G., Miglietta, A. M., and Maggiolini, M. (2019). Differential microRNA landscape triggered by estrogens in cancer associated fibroblasts (CAFs) of primary and metastatic breast tumors. Cancers 11:412. doi: 10.3390/cancers11030412

Wang, J.-W., Wu, X.-F., Gu, X.-J., and Jiang, X.-H. (2019). Exosomal miR1228 from cancer-associated fibroblasts promotes cell migration and invasion of osteosarcoma by directly targeting SCAI. Oncol. Res. 27, 979-986. doi: 10.3727/096504018X15336368805108

Wang, X., Zhang, L., Li, H., Sun, W., Zhang, H., and Lai, M. (2016). THBS2 is a potential prognostic biomarker in colorectal cancer. Sci. Rep. 6:33366. doi: $10.1038 /$ srep33366

Wang, Z., Tang, Y., Tan, Y., Wei, Q., and Yu, W. (2019). Cancer-associated fibroblasts in radiotherapy: challenges and new opportunities. Cell Commun. Signal. 17:47. doi: 10.1186/s12964-019-0362-2 
Wang, Z., Xiong, S., Mao, Y., Chen, M., Ma, X., Zhou, X., et al. (2016). Periostin promotes immunosuppressive premetastatic niche formation to facilitate breast tumour metastasis. J. Pathol. 239, 484-495. doi: 10.1002/path.4747

Webber, J. P., Spary, L. K., Sanders, A. J., Chowdhury, R., Jiang, W. G., Steadman, R., et al. (2015). Differentiation of tumour-promoting stromal myofibroblasts by cancer exosomes. Oncogene 34, 319-333. doi: 10.1038/onc.2013.560

Wei, L., Ye, H., Li, G., Lu, Y., Zhou, Q., Zheng, S., et al. (2018). Cancerassociated fibroblasts promote progression and gemcitabine resistance via the SDF-1/SATB-1 pathway in pancreatic cancer. Cell Death Dis. 9:1065. doi: 10.1038/s41419-018-1104-x

Westrich, J. A., Vermeer, D. W., Colbert, P. L., Spanos, W. C., and Pyeon, D. (2020). The multifarious roles of the chemokine CXCL14 in cancer progression and immune responses. Mol. Carcinog. 59, 794-806. doi: 10.1002/mc.23188

Willumsen, N., Ali, S. M., Leitzel, K., Drabick, J. J., Yee, N., Polimera, H. V., et al. (2019). Collagen fragments quantified in serum as measures of desmoplasia associate with survival outcome in patients with advanced pancreatic cancer. Sci. Rep. 9:19761. doi: 10.1038/s41598-019-56268-3

Wilson, T. R., Fridlyand, J., Yan, Y., Penuel, E., Burton, L., Chan, E., et al. (2012). Widespread potential for growth-factor-driven resistance to anticancer kinase inhibitors. Nature 487, 505-509. doi: 10.1038/nature11249

Wu, S., Zhang, Y., Xu, L., Dai, Y., Teng, Y., Ma, S., et al. (2012). Multicenter, randomized study of genetically modified recombinant human interleukin-11 to prevent chemotherapy-induced thrombocytopenia in cancer patients receiving chemotherapy. Support. Care Cancer 20, 1875-1884. doi: 10.1007/s00520-011-1290-x

Wu, X., Tao, P., Zhou, Q., Li, J., Yu, Z., Wang, X., et al. (2017). IL-6 secreted by cancer-associated fibroblasts promotes epithelial-mesenchymal transition and metastasis of gastric cancer via JAK2/STAT3 signaling pathway. Oncotarget 8, 20741-20750. doi: 10.18632/oncotarget.15119

Xiao, Q., Zhou, D., Rucki, A. A., Williams, J., Zhou, J., Mo, G., et al. (2016). Cancerassociated fibroblasts in pancreatic cancer are reprogrammed by tumorinduced alterations in genomic DNA methylation. Cancer Res. 76, 5395-5404. doi: 10.1158/0008-5472.CAN-15-3264

Xu, Y., Zhang, Z., Zhang, L., and Zhang, C. (2020). Novel module and hub genes of distinctive breast cancer associated fibroblasts identified by weighted gene co-expression network analysis. Breast Cancer 27, 1017-1028. doi: 10.1007/s12282-020-01101-3

Yamaguchi, H., and Sakai, R. (2015). Direct interaction between carcinoma cells and cancer associated fibroblasts for the regulation of cancer invasion. Cancers 7, 2054-2062. doi: 10.3390/cancers7040876

Yamanaka, T., Harimoto, N., Yokobori, T., Muranushi, R., Hoshino, K., Hagiwara, K., et al. (2020). Nintedanib inhibits intrahepatic cholangiocarcinoma aggressiveness via suppression of cytokines extracted from activated cancer-associated fibroblasts. Br. J. Cancer 122, 986-994. doi: 10.1038/s41416-020-0744-7

Yang, J., Lu, Y., Lin, Y. Y., Zheng, Z. Y., Fang, J. H., He, S., et al. (2016). Vascular mimicry formation is promoted by paracrine TGF- $\beta$ and SDF1 of cancerassociated fibroblasts and inhibited by miR-101 in hepatocellular carcinoma. Cancer Lett. 383, 18-27. doi: 10.1016/j.canlet.2016.09.012

Yang, L., Achreja, A., Yeung, T. L., Mangala, L. S., Jiang, D., Han, C., et al. (2016). Targeting stromal glutamine synthetase in tumors disrupts tumor microenvironment-regulated cancer cell growth. Cell Metab. 24, 685-700. doi: 10.1016/j.cmet.2016.10.011

Yang, L., Huang, J., Ren, X., Gorska, A. E., Chytil, A., Aakre, M., et al. (2008). Abrogation of TGF $\beta$ signaling in mammary carcinomas recruits Gr$1+\mathrm{CD} 11 \mathrm{~b}+$ myeloid cells that promote metastasis. Cancer Cell 13, 23-35. doi: 10.1016/j.ccr.2007.12.004

Yang, T., Deng, Z., Pan, Z., Qian, Y., Yao, W., and Wang, J. (2020). Prognostic value of periostin in multiple solid cancers: a systematic review with meta-analysis. J. Cell. Physiol. 235, 2800-2808. doi: 10.1002/jcp.29184

Yang, X., Li, Y., Zou, L., and Zhu, Z. (2019). Role of exosomes in crosstalk between cancer-associated fibroblasts and cancer cells. Front. Oncol. 9:356. doi: 10.3389/fonc.2019.00356

Yang, X., Lin, Y., Shi, Y., Li, B., Liu, W., Yin, W., et al. (2016). FAP Promotes immunosuppression by cancer-associated fibroblasts in the tumor microenvironment via STAT3-CCL2 Signaling. Cancer Res. 76, 4124-4135. doi: 10.1158/0008-5472.CAN-15-2973

Yano, S., Wang, W., Li, Q., Matsumoto, K., Sakurama, H., Nakamura, T., et al. (2008). Hepatocyte growth factor induces gefitinib resistance of lung adenocarcinoma with epidermal growth factor receptor-activating mutations. Cancer Res. 68, 9479-9487. doi: 10.1158/0008-5472.CAN-08-1643

Yu, B., Wu, K., Wang, X., Zhang, J., Wang, L., Jiang, Y., et al. (2018). Periostin secreted by cancer-associated fibroblasts promotes cancer stemness in head and neck cancer by activating protein tyrosine kinase 7. Cell Death Dis. 9:1082. doi: 10.1038/s41419-018-1116-6

Yu, S., Xia, S., Yang, D., Wang, K., Yeh, S., Gao, Z., et al. (2013). Androgen receptor in human prostate cancer-associated fibroblasts promotes prostate cancer epithelial cell growth and invasion. Med. Oncol. 30:674. doi: 10.1007/s12032-013-0674-9

Yue, H., Wang, J., Chen, R., Hou, X., Li, J., and Lu, X. (2019). Gene signature characteristic of elevated stromal infiltration and activation is associated with increased risk of hematogenous and lymphatic metastasis in serous ovarian cancer. BMC Cancer 19:1266. doi: 10.1186/s12885-019-6470-y

Yuzhalin, A. E., Urbonas, T., Silva, M. A., Muschel, R. J., and Gordon-Weeks, A. N. (2018). A core matrisome gene signature predicts cancer outcome. Br. J. Cancer 118, 435-440. doi: 10.1038/bjc.2017.458

Zhang, R., Qi, F., Zhao, F., Li, G., Shao, S., Zhang, X., et al. (2019). Cancerassociated fibroblasts enhance tumor-associated macrophages enrichment and suppress NK cells function in colorectal cancer. Cell Death Dis. 10:273. doi: 10.1038/s41419-019-1435-2

Zhang, Y., Cong, X., Li, Z., and Xue, Y. (2020). Estrogen facilitates gastric cancer cell proliferation and invasion through promoting the secretion of interleukin- 6 by cancer-associated fibroblasts. Int. Immunopharmacol. 78:105937. doi: 10.1016/j.intimp.2019.105937

Zhang, Z., Karthaus, W. R., Lee, Y. S., Gao, V. R., Wu, C., Russo, J. W., et al. (2020). Tumor microenvironment-derived NRG1 promotes antiandrogen resistance in prostate cancer. Cancer Cell 38, 279-296.e9. doi: 10.1016/j.ccell.2020.06.005

Zhao, F., Evans, K., Xiao, C., deVito, N., Theivanthiran, B., Holtzhausen, A., et al. (2018). Stromal fibroblasts mediate anti-PD-1 resistance via MMP-9 and dictate $\mathrm{TGFb}$ inhibitor sequencing in melanoma. Cancer Immunol. Res. 6, 1459-1471. doi: 10.1158/2326-6066.CIR-18-0086

Zhou, X., Yan, T., Huang, C., Xu, Z., Wang, L., Jiang, E., et al. (2018). Melanoma cell-secreted exosomal miR-155-5p induce proangiogenic switch of cancerassociated fibroblasts via SOCS1/JAK2/STAT3 signaling pathway. J. Exp. Clin. Cancer Res. 37:242. doi: 10.1186/s13046-018-0911-3

Zhou, Z., Zhou, Q., Wu, X., Xu, S., Hu, X., Tao, X., et al. (2020). VCAM-1 secreted from cancer-associated fibroblasts enhances the growth and invasion of lung cancer cells through AKT and MAPK signaling. Cancer Lett. 473, 62-73. doi: 10.1016/j.canlet.2019.12.039

Zhuang, J., Lu, Q., Shen, B., Huang, X., Shen, L., Zheng, X., et al. (2015). TGF $\beta 1$ secreted by cancer-associated fibroblasts induces epithelial-mesenchymal transition of bladder cancer cells through lncRNA-ZEB2NAT. Sci. Rep. 5:11924. doi: 10.1038/srep11924

Ziani, L., Safta-Saadoun, B. T., G.ourbeix, J., Cavalcanti, A., Robert, C., Favre, G., et al. (2017). Melanoma-associated fibroblasts decrease tumor cell susceptibility to NK cell-mediated killing through matrix-metalloproteinases secretion. Oncotarget 8, 19780-19794. doi: 10.18632/oncotarget. 15540

Conflict of Interest: The authors declare that the research was conducted in the absence of any commercial or financial relationships that could be construed as a potential conflict of interest.

Copyright (c) 2021 Linares, Marín-Jiménez, Badia-Ramentol and Calon. This is an open-access article distributed under the terms of the Creative Commons Attribution License (CC BY). The use, distribution or reproduction in other forums is permitted, provided the original author(s) and the copyright owner(s) are credited and that the original publication in this journal is cited, in accordance with accepted academic practice. No use, distribution or reproduction is permitted which does not comply with these terms. 